Article

\title{
Esophageal Squamous Cell Carcinoma Is Accompanied by Local and Systemic Changes in L-arginine/NO Pathway
}

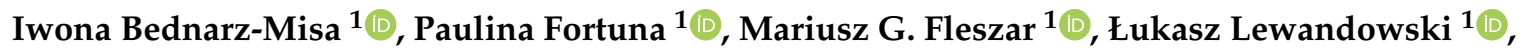 \\ Dorota Diakowska $^{2,3}\left({ }^{(0)}\right.$, Joanna Rosińczuk ${ }^{3}(\mathbb{1})$ and Małgorzata Krzystek-Korpacka ${ }^{1, *(1)}$ \\ 1 Department of Medical Biochemistry, Wroclaw Medical University, 50-368 Wroclaw, Poland; \\ iwona.bednarz-misa@umed.wroc.pl (I.B.-M.); paulina.fortuna@umed.wroc.pl (P.F.); \\ fleszar.mariusz@gmail.com (M.G.F.); lukasz.lewandowski@umed.wroc.pl (Ł.L.) \\ 2 Department of Gastrointestinal and General Surgery, Wroclaw Medical University, 50-368 Wroclaw, Poland; \\ dorota.diakowska@umed.wroc.pl \\ 3 Department of Nervous System Diseases, Wroclaw Medical University, 51-618 Wroclaw, Poland; \\ joanna.rosinczuk@umed.wroc.pl \\ * Correspondence: malgorzata.krzystek-korpacka@umed.wroc.pl
}

Received: 5 August 2020; Accepted: 28 August 2020; Published: 30 August 2020

\begin{abstract}
The L-arginine/NO pathway holds promise as a source of potential therapy target and biomarker; yet, its status and utility in esophageal squamous cell carcinoma (ESCC) is unclear. We aimed at quantifying pathway metabolites in sera from patients with ESCC $(n=61)$ and benign conditions $(n=62)$ using LC-QTOF-MS and enzyme expression in esophageal tumors and matched noncancerous samples $(n=40)$ using real-time PCR with reference to ESCC pathology and circulating immune/inflammatory mediators, quantified using Luminex xMAP technology. ESCC was associated with elevated systemic arginine and asymmetric dimethylarginine. Citrulline decreased and arginine bioavailability increased along with increasing ESCC advancement. Compared to adjacent tissue, tumors overexpressed ODC1, NOS2, PRMT1, and PRMT5 but had downregulated ARG1, ARG2, and DDAH1. Except for markedly higher NOS2 and lower ODC1 in tumors from M1 patients, the pathology-associated changes in enzyme expression were subtle and present also in noncancerous tissue. Both the local enzyme expression level and systemic metabolite concentration were related to circulating inflammatory and immune mediators, particularly those associated with eosinophils and those promoting viability and self-renewal of cancer stem cells. Metabolic reprogramming in ESCC manifests itself by the altered L-arginine/NO pathway. Upregulation of PRMTs in addition to NOS2 and $O D C 1$ and the pathway link with stemness-promoting cytokines warrants further investigation.
\end{abstract}

Keywords: asymmetric dimethylarginine (ADMA); symmetric dimethylarginine (SDMA); ornithine; citrulline; dimethylamine (DMA); arginase (ARG); nitric oxide synthase (NOS); protein arginine N-methyltransferase (PRMT); dimethylarginine dimethylaminohydrolase (DDAH); ornithine decarboxylase (ODC)

\section{Introduction}

Squamous cell carcinoma of the esophagus (ESCC) is the dominant type of esophageal cancerand one of the deadliest and understudied malignancies worldwide. The etiology of ESCC differs by geographic region with smoking and heavy alcohol consumption considered synergistic primary causes in Western European countries. New potential factors, such as polycyclic aromatic hydrocarbons; diet-low in antioxidants and contaminated with mycotoxins and nitrosamines; and the oral microbiome, are still emerging. [1,2] High case fatality rates, approaching 90\%, result from delayed 
diagnosis and major trauma associated with esophageal surgery. Unlike in many other cancers, hereditary forms are rare, there is no clear premalignant stage, and early stages of the disease are asymptomatic. Moreover, the first clinical symptoms are nonspecific and easy to overlook. Consequently, the ESCC is mostly diagnosed at an advanced stage, precluding curative tumor resection. Surgery remains the only curative modality but constitutes a challenge owing to the fact that esophagus spans three anatomic compartments and is located in close proximity to several vital organs [2]. Better understanding of molecular landscape facilitating development of targeted treatment strategies and biomarker discovery is prerequisite for improving prognosis of ESCC patients. Still, the approach, referred to as "precision/personalized medicine", is only starting to be implemented in ESCC, and first potential therapy targets have recently been identified using next-generation sequencing (NGS) [3].

Metabolic reprogramming is one of eight recognized cancer hallmarks [4], allowing increasing demands of intensively proliferating cancer cells for energy and intermediates to be met. There is growing awareness that the process is highly dynamic. Changes in the metabolic make-up of cancer cells in localized primary tumors are distinct from those necessary to facilitate cancer cell dissemination and growth in distant organs [5]. Our preliminary research has shown that ESCC might be locally characterized by upregulated expression of genes encoding glucose transporter 1 (GLUT1) as well as inducible nitric oxide synthase (NOS) and ornithine decarboxylase (ODC) of the L-arginine/nitric oxide (NO)/polyamine pathway [6]. In the present study, we conducted a comprehensive analysis of the L-arginine/NO pathway status at the local transcriptomic and systemic metabolic level, in order to screen for potential molecular therapy targets and biomarkers, respectively. Alterations in the pathway metabolites as well as their suitability as diagnostic tools have recently been demonstrated by our group in colorectal cancer (CRC) [7] and inflammatory bowel disease, the condition associated with increased CRC risk [8].

L-arginine, further referred to as arginine, is a conditionally essential amino acid and a source of various biologically active metabolites, including NO-synthesized by NOS enzymes and ornithine-synthesized by arginases (ARG) and used by ODC for the production of polyamines. Arginine plays a dual role in cancer. On the one hand, it is necessary for immune cells to fight against the disease. Its accelerated uptake and metabolism by cancer cells is a strategy of immune evasion and, therefore, arginine supplementation is viewed as an antineoplastic therapeutic approach. On the other hand, both arginine and its metabolic products, particularly polyamines, facilitate tumor growth and metastasis [9-12]. It has been demonstrated in a mice model of breast cancer that a shift towards arginase and polyamine synthesis is a hallmark of early metastatic disease [13]. Exploiting cancer requirement for arginine by upregulating endogenous or supplementing exogenous arginine-consuming enzymes is considered for arginine-auxotrophic cancers [11,12].

Nitric oxide synthesis by NOS enzymes is regulated by arginine availability, controlled by asymmetric (ADMA) and symmetric dimethylarginine (SDMA) and ornithine at the level of cationic amino acid transporter (CAT-1), as well as by enzyme inhibition by ADMA and, to a much lesser degree, by SDMA. Dimethylarginines are products of degradation of methylated proteins. Methyl groups are attached by arginine N-methyltransferases (PRMT), consisting of type I enzymes (e.g., PRMT1), which yield ADMA after proteolysis and type II enzymes (e.g., PRMT5), which yield SDMA. SDMA is mainly excreted with urine while ADMA is catabolized by dimethylarginine dimethylaminohydrolase (DDAH) into citrulline and dimethylamine (DMA) [9-12,14]. A schematic representation of the L-arginine/NO pathway is depicted in Figure 1.

In view of a pressing need for new therapeutic targets and biomarkers, the aim of the present study was to investigate the L-arginine/NO pathway status in ESCC. We analyzed the pathway metabolites (arginine, citrulline, ornithine, ADMA, SDMA, and DMA) at the systemic level, referring them to ESCC advancement and putting them into the broad context of the inflammatory, immune and angiogenic milieu. Two indices, surrogate indicators of arginine general bioavailability (arginine-to-(citrulline+ornithine) ratio) and of its availability for NO synthesis (arginine-to-ADMA ratio), were calculated as well. We also determined the suitability of pathway metabolites and 
metabolite-derived indices as differential markers in ESCC. In addition, the local expression of key pathway enzymes (ARG1, ARG2, DDAH1, DDAH2, NOS2, ODC1, PRMT1, and PRMT5), as potential therapeutic targets, was evaluated in reference to cancer pathology.

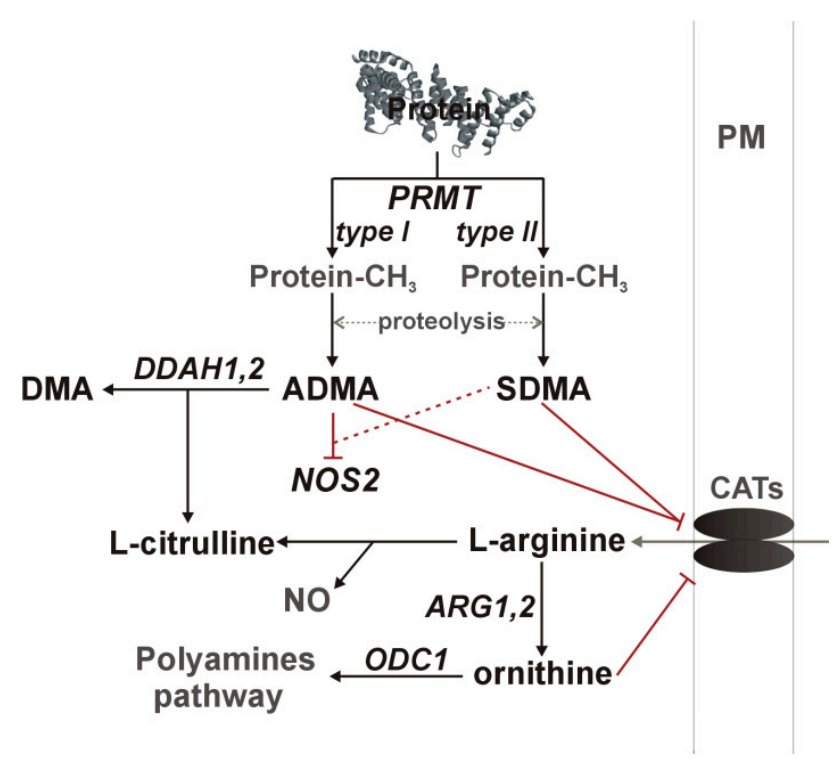

Figure 1. A simplified overview of the L-arginine/NO pathway. Pathway enzymes are written in italics and metabolites in a straight script; gray color was used to indicate pathway components not determined in the current study. Inhibitory effects are marked in red, with dashed line if the effect is weak. ADMA, asymmetric dimethylarginine; ARG, arginase; CATs, cationic amino acid transporter; DDAH, dimethylarginine dimethylaminohydrolase; DMA, dimethylamine; NOS, nitric oxide synthase; ODC, ornithine decarboxylase; PM, plasma membrane; PRMT, protein methyltransferase.

\section{Results}

\subsection{Systemic Concentrations of L-arginine/NO Pathway Metabolites}

\subsubsection{L-arginine/NO Pathway Metabolites in ESCC and Benign Conditions}

Systemic concentration of the pathway metabolites was determined using LC-QTOF-MS (liquid chromatography quadrupole time-of-flight mass spectrometry) in 61 patients with ESCC and 62 individuals with benign conditions of the esophagus. Both groups were well age and sex matched. The ESCC patients had higher arginine and ADMA than individuals with benign conditions of the esophagus. There was no significant difference in the Arg/ADMA ratio, indicative of arginine availability for NO synthesis, but the general arginine bioavailability was greater in ESCC as indicated by the higher $\mathrm{Arg} /(\mathrm{Cit}+\mathrm{Orn})$ ratio. The other metabolites, that is, citrulline, ornithine, SDMA, and DMA, did not differ between groups (Figure 2).

There were 16 patients with resected tumors of esophagus admitted three months postsurgery for the esophagoplasty. We compared the systemic concentration of metabolites between those patients and the ESCC group and found that ESCC patients tended to have higher arginine (124.8 $\mu \mathrm{M}(116-135) \mathrm{vs}$. $112.4 \mu \mathrm{M}(88-125), p=0.058)$ and ADMA $(0.43 \mu \mathrm{M}(0.40-0.44)$ vs. $0.38 \mu \mathrm{M}(0.31-0.45), p=0.081)$ than esophagoplasty patients. In turn, esophagoplasty patients were distinguished by a significantly higher concentration of SDMA than ESCC patients $(0.42 \mu \mathrm{M}(0.35-0.44)$ vs. $0.35 \mu \mathrm{M}(0.33-0.38), p=0.025)$. 


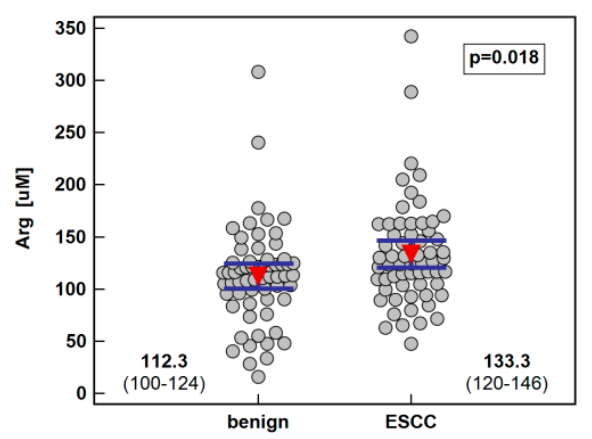

(a)

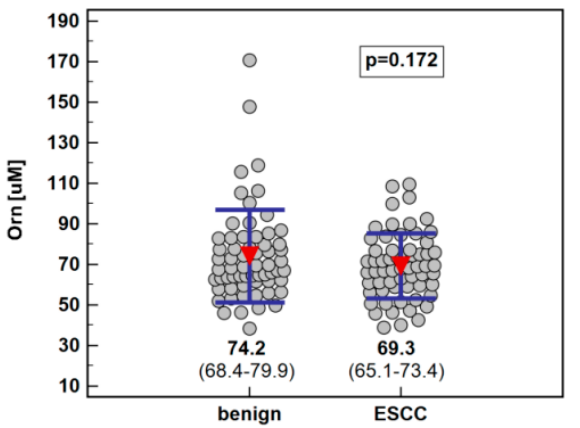

(c)

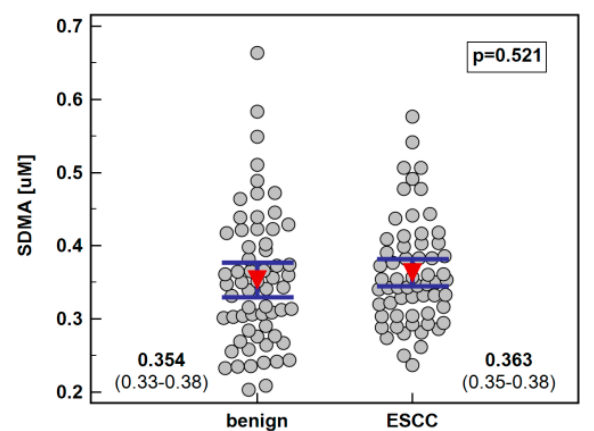

(e)

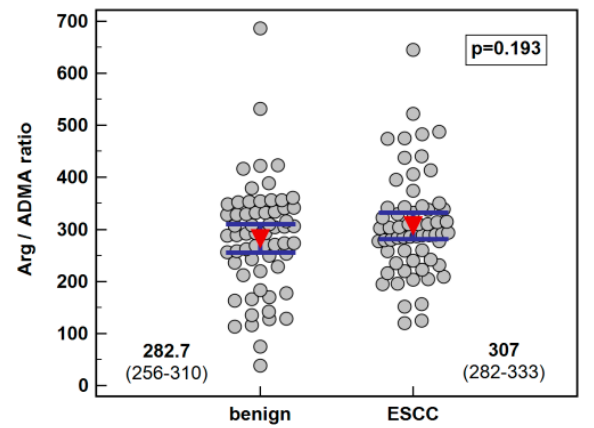

(g)

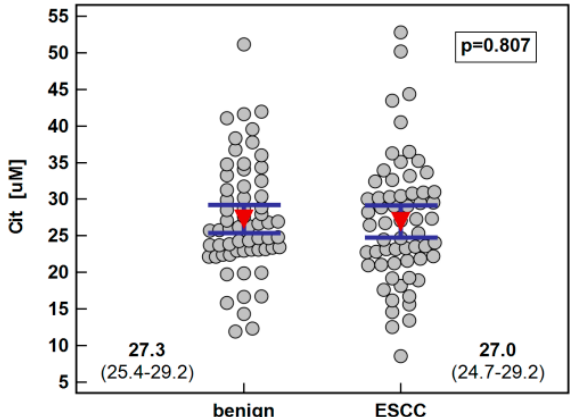

(b)

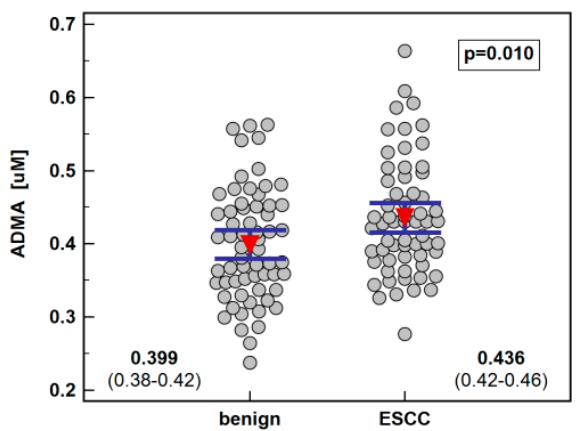

(d)

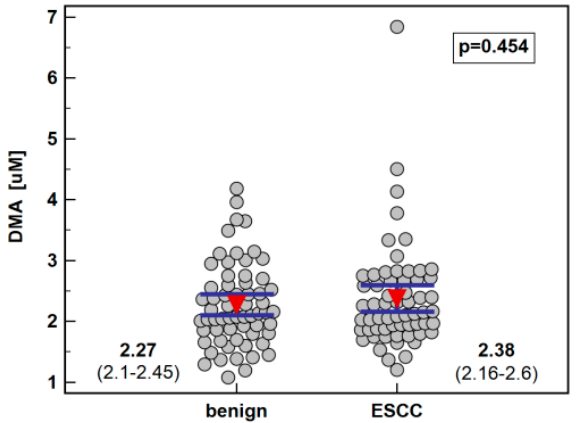

(f)

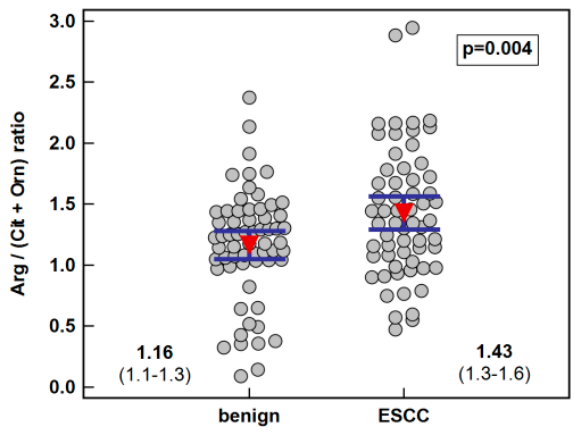

(h)

Figure 2. Systemic concentration of L-arginine/NO pathway metabolites in patients with esophageal squamous cell carcinoma (ESCC; $n=61)$ and individuals with benign conditions of the esophagus ( $n=62)$ : (a) arginine (Arg); (b) citrulline (Cit); (c) ornithine (Orn); (d) asymmetric dimethylarginine (ADMA); (e) symmetric dimethylarginine (SDMA); (f) dimethylamine (DMA); (g) arginine-to-ADMA ratio (Arg/ADMA); (h) arginine-to-(citrulline+ornithine) (Arg/(Cit+Orn). Data presented as the means with $95 \%$ confidence interval (red triangles with whiskers as well as numeric data) and analyzed using a $t$-test for independent samples. 


\subsubsection{Association of L-arginine/NO Pathway Metabolites with ESCC Advancement}

The analysis of the metabolite concentration against ESCC advancement showed that only citrulline was significantly associated with the disease overall stage (TNM) as well as all its components: primary tumor extension, lymph node involvement, and distant metastasis. The metabolite concentration dropped along with increasing stage $(\rho=-0.55, p<0.0001)$, being significantly lower in stage IV than I or II, and along with primary tumor extension $(\rho=-0.47, p=0.0001)$, being significantly lower in T4 than T1 or T3. Citrulline was significantly lower in ESCC patients with lymph node or distant metastases (Figure 3).

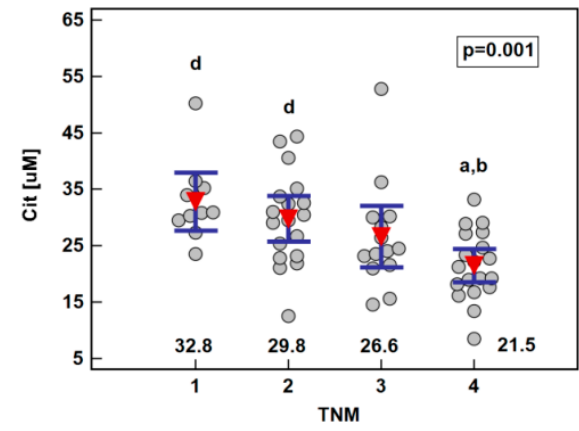

(a)

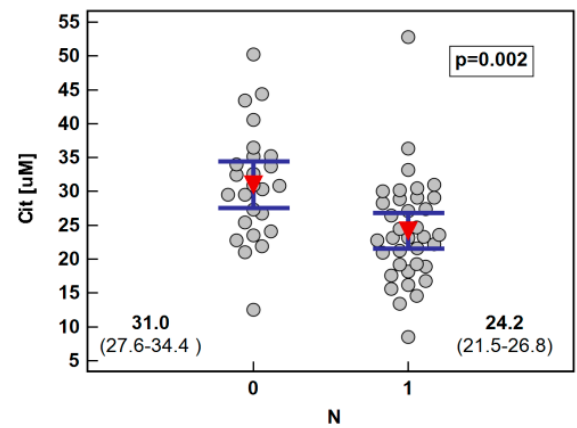

(c)

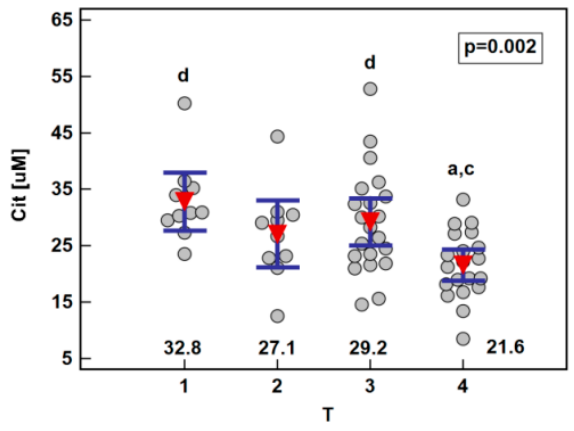

(b)

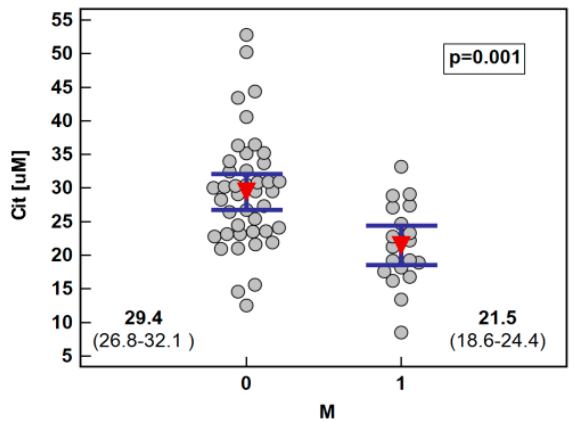

(d)

Figure 3. Association between systemic citrulline (Cit) concentration and ESCC advancement: (a) tumor-node-metastasis (TNM) stage; (b) primary tumor extension (T); (c) lymph node involvement $(\mathrm{N})$; (d) distant metastasis (M). Data presented as the means with $95 \%$ confidence interval (red triangles with whiskers as well as numeric data) and analyzed using one-way ANOVA. a, significantly different from T1; b, significantly different from T2; c, significantly different from T3; d, significantly different from $\mathrm{T} 4$.

Except for arginine elevation in patients with T3 cancers, no other metabolite was significantly associated with the disease advancement. Consequently, arginine-based ratios, Arg/ADMA and Arg/(Cit+Orn), were significantly higher in T3 cancers as well (Figure 4). Owing to the gradual citrulline depletion with the disease advancing, Arg/(Cit+Orn) correlated with TNM $(\rho=0.27, p=0.036)$ and T $(\rho=0.29, p=0.023)$. The association between the arginine and T stage remained significant $(p=0.029)$ following the removal of two outlying observations in T3 cancers, although the difference between T2 and T3 lost significance. 


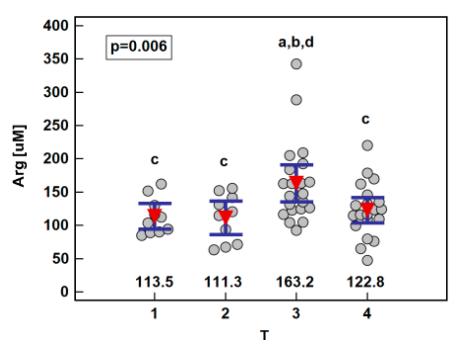

(a)

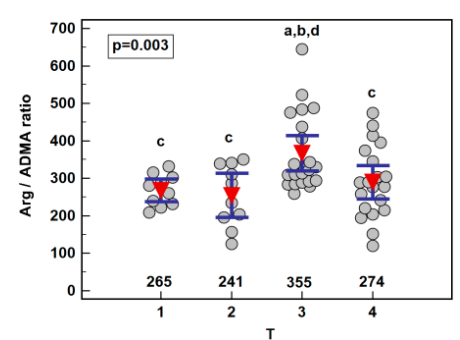

(b)

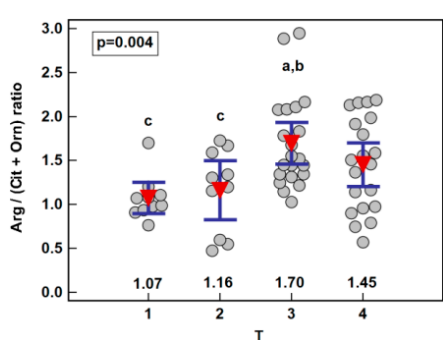

(c)

Figure 4. Association between systemic arginine concentration or arginine-based ratios and primary tumor extension $(\mathrm{T})$ in patients with esophageal squamous cell carcinoma: (a) arginine (Arg); (b) arginine-to-ADMA ratio (Arg/ADMA); (c) arginine-to-(citrulline+ornithine) (Arg/(Cit+Orn)). Data presented as the means with 95\% confidence interval (red triangles with whiskers as well as numeric data) and analyzed using one-way ANOVA. a, significantly different from $\mathrm{T} 1$; $\mathrm{b}$, significantly different from T2; c, significantly different from T3; d, significantly different from T4.

\subsubsection{L-arginine/NO Pathway Metabolites as Differential Markers}

Pathway metabolites, which were significantly different in patients with ESCC and benign esophageal conditions, were analyzed as potential differential markers using receiver operating curve (ROC) analysis. The individual performance of the arginine, ADMA, and Arg/(Cit+Orn) ratio was very comparable, although arginine and $\mathrm{Arg} /(\mathrm{Cit}+\mathrm{Orn})$ had superior specificity and ADMA-sensitivity. Logistic regression (stepwise method) was applied to identify the independent predictors of ESCC. The ADMA and Arg/(Cit-Orn) were selected, and predicted probabilities were used in a ROC curve analysis to assess the diagnostic power of their concomitant assessment. The overall accuracy of the ADMA and Arg/(Cit-Orn) panel improved only minimally (Figure 5).

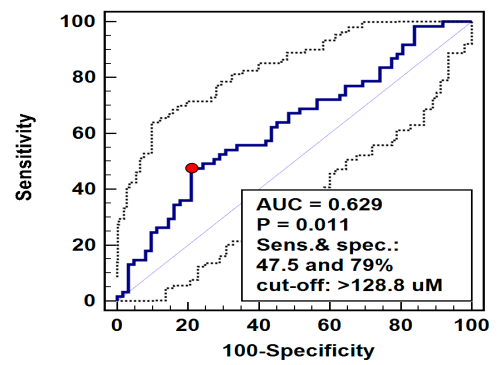

(a)

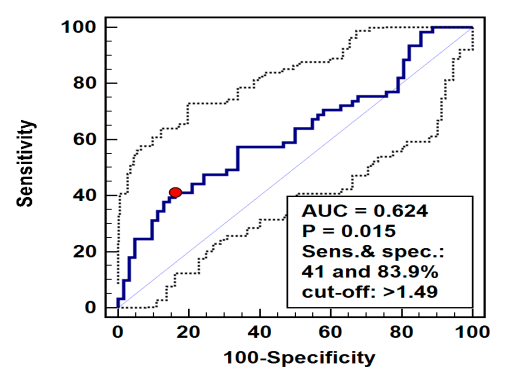

(c)

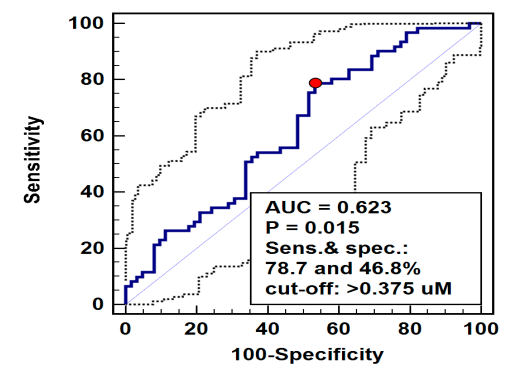

(b)

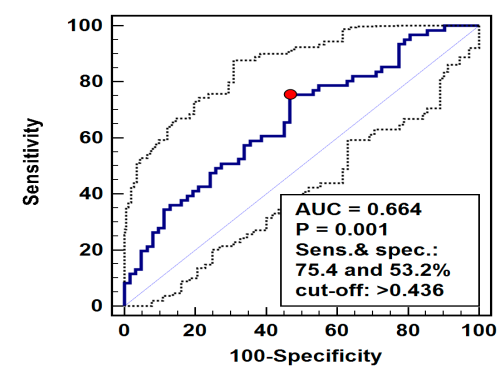

(d)

Figure 5. Receiver operating curve (ROC) analysis of diagnostic potential of L-arginine pathway metabolites in differentiating esophageal squamous cell carcinoma (ESCC) from benign conditions: (a) arginine (Arg); (b) asymmetric dimethylarginine (ADMA); (c) arginine-to-(citrulline+ornithine) ratio (Arg/(Cit+Orn)); (d) panel consisting of ADMA and Arg/(Cit+Orn). Graphs present ROC curve (solid curve) with 95\% confidence interval (dotted curves) and an optimal cut-off value (red dot). Performance of a chance marker devoid of diagnostic power (AUC $=0.5$ ) is indicated by a diagonal line. AUC, area under ROC curve; Sens., sensitivity; spec., specificity. 
2.1.4. Interrelationship between Systemic Concentrations of L-arginine/NO Pathway Metabolites

The interrelationship between systemic concentrations of L-arginine/NO pathway metabolites in ESCC patients and individuals with benign conditions of the esophagus was compared (Table 1). ADMA was positively correlated with all other metabolites in both ESCC and patients with benign conditions; although in ESCC, the correlation was stronger with arginine and SDMA and in patients with benign conditions with citrulline. Arginine was correlated positively with citrulline in both groups but with SDMA only in ESCC. Citrulline correlated with arginine and tended to with ADMA in ESCC; while in benign conditions, its correlation with ADMA was stronger, and there was positive correlation with DMA as well. DMA was the most strongly correlated with SDMA in both groups and with ADMA in ESCC rather than with citrulline like in the benign group. Ornithine correlated weakly with ADMA in both groups and with SDMA in ESCC patients. SDMA was correlated with ADMA and SDMA in both groups but only with arginine and ornithine in ESCC.

Table 1. Interrelationship between systemic concentrations of L-arginine/NO pathway metabolites in patients with esophageal squamous cell carcinoma (ESCC) or benign conditions of the esophagus.

\begin{tabular}{cccccccc}
\hline Metabolite & ADMA & Arg & Cit & DMA & Orn & SDMA \\
\hline & \multicolumn{7}{c}{ Metabolites in ESCC patients } \\
ADMA & $\mathrm{x}$ & $0.43^{3}$ & $0.25^{4}$ & $0.32^{1}$ & $0.33^{2}$ & $0.44^{3}$ \\
Arg & $0.39^{2}$ & $\mathrm{x}$ & $0.40^{2}$ & - & - & $0.29^{1}$ \\
Cit & $0.47^{3}$ & $0.30^{1}$ & $\mathrm{x}$ & - & - & - \\
DMA & $0.22^{4}$ & - & $0.30^{1}$ & $\mathrm{x}$ & - & $0.46^{3}$ \\
Orn & $0.28^{1}$ & - & $0.24^{4}$ & - & $\mathrm{x}$ & $0.35^{2}$ \\
SDMA & $0.35^{2}$ & - & - & $0.45^{3}$ & - & $\mathrm{x}$ \\
& Metabolites in patients with benign diseases &
\end{tabular}

Data presented as Pearson correlation coefficient (r). ADMA, asymmetric dimethylarginine; Arg, arginine; Cit, citrulline; DMA, dimethylamine; Orn, ornithine; SDMA, symmetric dimethylarginine; ${ }^{1}, p<0.05 ;{ }^{2}, p<0.01$; ${ }^{3}, p<0.001 ;{ }^{4}, 0.05<p<0.1 ;-$, no significant association or tendency $(p>0.1)$.

2.1.5. Interplay Between L-arginine/NO Pathway Metabolites and Circulating Cytokines and Growth Factors

Arginine was rather poorly interrelated with circulating inflammatory, immune, and angiogenic mediators. There was a fair positive correlation with hepatocyte growth factor (HGF) and tumor necrosis factor (TNF)-related apoptosis inducing ligand (TRAIL) and a slightly weaker association with TNF $\alpha$, monocyte chemoattractant protein (MCP)-1, platelet-derived growth factor (PDGF)-BB, and stem cell factor (SCF). Ornithine displayed a fair negative correlation with IL-7 and a positive one with macrophage migration inhibitory factor (MIF). In turn, citrulline was tightly, although negatively, correlated with a number of circulating cytokines and growth factors. It displayed a moderate inverse correlation with IL-13 and fair negative correlations with the following cytokines (ordered by decreasing strength): interferon (IFN)- $\gamma$, IL-10 and macrophage inflammatory protein (MIP)-1 $\beta$, granulocyte-macrophage colony-stimulating factor (GM-CSF) and IL-5, IL-17 and TNF $\alpha$, fibroblast growth factor (FGF)2, granulocyte colony-stimulating factor (G-CSF) and IL-1 $\beta$, IL-1ra and IL-8, IL-4, MIF, IL-6, IL-12p70 and MIP-1 $\alpha$, IL-15, eotaxin, and leukemia inhibitory factor (LIF) (Table 2).

The ADMA displayed the strongest fair positive correlation with growth-regulated alpha protein $(\mathrm{GRO} \alpha)$, followed by TRAIL, IFN $\alpha 2$, IL-3 and interleukin 2 receptor subunit $\alpha$ (IL-2R $\alpha$ ), stromal cell-derived factor (SDF)-1 $\alpha$, C-C motif chemokine ligand 27 (CTAK), and nerve growth factor $\beta$ ( $\beta$-NGF) and HGF. The SDMA was more tightly related to circulating cytokines. It was the most strongly correlated with SCF and displayed a fair positive correlation also with CTAK, LIF, IL-3, IFN $\gamma$-induced protein 10 (IP-10), MIP- $1 \alpha$, and stem cell growth factor $\beta$ (SCGF- $\beta$ ), $\beta$-NGF and GRO $\alpha$, IFN $\alpha 2$, SDF- $1 \alpha$, IL-13, HGF and monokine induced by gamma interferon (MIG), GM-CSF and IL-15, IL-16, and MIP-1 $\beta$. The DMA displayed a moderate positive correlation with SCF and a fair correlation with SCGF- $\beta$, TRAIL, IL-16, HGF, IL-3, IL-2R $\alpha$ and LIF, GRO $\alpha$ and IFN $\alpha 2, \beta$-NGF and IL-19, and MIP- $1 \beta$ and SDF- $1 \alpha$ (Table 2). 
Table 2. Correlation between systemic concentration of L-arginine/NO pathway metabolites and circulating cytokines, chemokines, and growth factors.

\begin{tabular}{|c|c|c|c|c|c|c|c|c|}
\hline Cytokine & Arg & Cit & Orn & ADMA & SDMA & DMA & A/ADMA & $\mathrm{A} / \mathrm{C}+\mathrm{O}$ \\
\hline$\beta-N G F$ & - & - & - & $0.31^{1}$ & $0.42^{2}$ & $0.32^{1}$ & - & - \\
\hline СТАК & - & - & - & $0.33^{1}$ & $0.48^{3}$ & - & - & $0.35^{1}$ \\
\hline EOX & - & $0.30^{1}$ & - & - & - & - & - & - \\
\hline FGF2 & - & $-0.50^{3}$ & - & - & - & - & - & - \\
\hline G-CSF & - & $-0.45^{2}$ & - & - & - & - & - & - \\
\hline GM-CSF & - & $-0.54^{3}$ & - & - & $0.33^{1}$ & - & - & $0.28^{4}$ \\
\hline $\mathrm{GRO} \alpha$ & - & - & - & $0.49^{3}$ & $0.42^{2}$ & $0.34^{1}$ & - & - \\
\hline HGF & $0.42^{2}$ & - & - & $0.31^{1}$ & $0.34^{1}$ & $0.41^{2}$ & - & - \\
\hline IFN $\alpha 2$ & - & - & - & $0.42^{2}$ & $0.41^{2}$ & $0.34^{1}$ & - & - \\
\hline $\operatorname{IFN} \gamma$ & - & $-0.57^{3}$ & - & - & - & - & - & - \\
\hline IL-10 & - & $-0.55^{3}$ & - & - & - & - & - & - \\
\hline IL-12p70 & - & $-0.33^{1}$ & - & - & - & - & $-0.27^{4}$ & - \\
\hline IL-13 & - & $-0.64^{3}$ & - & - & $0.36^{1}$ & $0.26^{4}$ & - & - \\
\hline IL-15 & - & $-0.31^{1}$ & - & - & $0.33^{1}$ & - & - & - \\
\hline IL-16 & - & - & - & - & $0.32^{1}$ & $0.44^{2}$ & - & - \\
\hline IL-17 & - & $-0.51^{3}$ & - & - & $0.29^{4}$ & - & - & $0.41^{2}$ \\
\hline IL-18 & $0.27^{4}$ & - & & $0.27^{4}$ & $0.29^{4}$ & $0.32^{1}$ & - & - \\
\hline IL-1 $\beta$ & - & $-0.45^{2}$ & - & - & - & - & - & $0.32^{1}$ \\
\hline IL-1ra & - & $-0.44^{2}$ & - & - & - & - & - & - \\
\hline IL-2R $\alpha$ & - & - & - & $0.40^{2}$ & $0.26^{1}$ & $0.38^{2}$ & $-0.29^{4}$ & - \\
\hline IL-3 & - & - & - & $0.40^{2}$ & $0.45^{2}$ & $0.39^{3}$ & - & - \\
\hline IL-4 & - & $-0.38^{2}$ & - & - & - & - & - & - \\
\hline IL-5 & - & $-0.54^{3}$ & - & - & - & - & - & - \\
\hline IL-6 & - & $-0.35^{1}$ & - & - & - & - & - & - \\
\hline IL-7 & - & - & $-0.51^{3}$ & - & - & - & - & $0.39^{2}$ \\
\hline IL-8 & - & $-0.44^{2}$ & - & - & - & - & - & - \\
\hline IL-9 & - & $-0.26^{4}$ & - & - & $0.27^{4}$ & - & - & - \\
\hline IP-10 & - & - & - & - & $0.45^{2}$ & - & - & - \\
\hline LIF & - & $-0.29^{1}$ & - & - & $0.47^{2}$ & $0.38^{2}$ & - & $0.27^{4}$ \\
\hline MCP-1 & $0.30^{1}$ & - & - & - & $0.29^{1}$ & - & - & - \\
\hline MIF & - & $-0.37^{1}$ & $0.30^{1}$ & - & - & - & $-0.32^{1}$ & $-0.32^{1}$ \\
\hline MIG & - & - & - & $0.25^{4}$ & $0.34^{1}$ & - & - & - \\
\hline MIP- $1 \alpha$ & - & $-0.33^{1}$ & - & - & $0.45^{2}$ & - & - & - \\
\hline MIP-1 $\beta$ & - & $-0.55^{3}$ & - & - & $0.31^{1}$ & $0.31^{1}$ & - & - \\
\hline PDGF-BB & $0.32^{1}$ & - & - & - & $0.26^{4}$ & $0.27^{4}$ & $0.33^{1}$ & - \\
\hline SCF & $0.30^{1}$ & - & - & $0.28^{4}$ & $0.54^{3}$ & $0.64^{3}$ & - & - \\
\hline SCGF- $\beta$ & - & - & - & - & $0.45^{2}$ & $0.49^{3}$ & - & - \\
\hline SDF-1 $\alpha$ & - & - & - & $0.35^{1}$ & $0.37^{1}$ & $0.31^{1}$ & - & - \\
\hline $\mathrm{TNF} \alpha$ & $0.36^{1}$ & $-0.51^{3}$ & - & - & $0.27^{4}$ & - & - & $0.31^{1}$ \\
\hline TRAIL & $0.47^{3}$ & - & - & $0.43^{2}$ & - & $0.48^{3}$ & - & $0.28^{4}$ \\
\hline VEGF-A & - & $-0.26^{4}$ & - & - & - & - & $-0.35^{1}$ & - \\
\hline
\end{tabular}

Data present Spearman rank correlation coefficients $\rho$ (rho). Only significant correlations or tendencies are included. Statistical significance is indicated by number in superscript: ${ }^{1}, p<0.05{ }^{2}, p<0.01 ;{ }^{3}, p<0.001 ;{ }^{4}$, tendency $0.05<p<0.1$. Lack of significant correlation or tendency is denoted by "-". Arg, arginine; Cit, citrulline; Orn, ornithine; ADMA, asymmetric dimethylarginine; SDMA, symmetric dimethylarginine; DMA, dimethylamine; A/ADMA, arginine-to-ADMA ratio; $\mathrm{A} / \mathrm{C}+\mathrm{O}$, arginine-to-(citrulline+ornithine) ratio; $\beta$-NGF, nerve growth factor $\beta$; CTAK, C-C motif chemokine ligand 27 (CCL27); EOX, eotaxin 1 (CCL11); FGF2, fibroblast growth factor $\beta$; G-CSF, granulocyte colony-stimulating factor; GM-CSF, granulocyte-macrophage colony-stimulating factor; GROa, growth-regulated alpha protein (CXCL1); HGF, hepatocyte growth factor; IFN, interferon; IL, interleukin; IL-1ra, interleukin-1 receptor antagonist; IL-2R $\alpha$, interleukin 2 receptor subunit $\alpha$; IP-10, interferon gamma-induced protein 10 (CXCL10); LIF, leukemia inhibitory factor; MCP-1, monocyte chemoattractant protein 1; MIF, macrophage migration inhibitory factor; MIG, monokine induced by gamma interferon (CXCL9); MIP, macrophage inflammatory protein; PDGF-BB, platelet-derived growth factor BB; SCF, stem cell factor; SCGF $\beta$, stem cell growth factor $\beta$; SDF- $1 \alpha$, stromal cell-derived factor $1 \alpha$; TNF $\alpha$, tumor necrosis factor $\alpha$; TRAIL, tumor necrosis factor (TNF)-related apoptosis inducing ligand; VEGF-A, vascular endothelial growth factor A. 
The arginine bioavailability index (Arg/(Cit+Orn)) correlated positively with IL-17, followed by IL-7, CTAK, IL-1 $\beta$, and TNF $\alpha$ and negatively with MIF. Arginine availability for NO synthesis (Arg/ADMA) was positively related to PDGF-BB concentration and negatively to vascular endothelial growth factor (VEGF)-A and MIF (Table 2).

\subsection{Transcriptional Analysis of Local Expression of Key L-arginine/NO Pathway Enzymes}

\subsubsection{Pairwise Analysis of Enzyme Expression in Tumor and Adjacent Tissue}

Quantitative (real-time) polymerase chain reaction (PCR) with SYBR Green chemistry was used to determine the relative expression level of ARG1 and ARG2, DDAH1 and DDAH2, NOS2, ODC1, and PRMT1 and PRMT5 in 40 patient-matched samples from esophageal tumors and adjacent, macroscopically normal mucosa.

Both ARG1 (by 4.9-fold) and ARG2 (1.5-fold) were significantly downregulated in tumors as compared to adjacent tissue. The DDAH1 was downregulated as well (by 1.5-fold), while DDAH2 expression did not differ. The NOS2 (by 8.7-fold) and ODC1 (5.4-fold) expression was upregulated in tumors. Likewise, PRMT1 (by 1.8-fold) and PRMT5 (by 1.6-fold) expression in tumors was higher than in noncancerous adjacent mucosa (Figure 6).

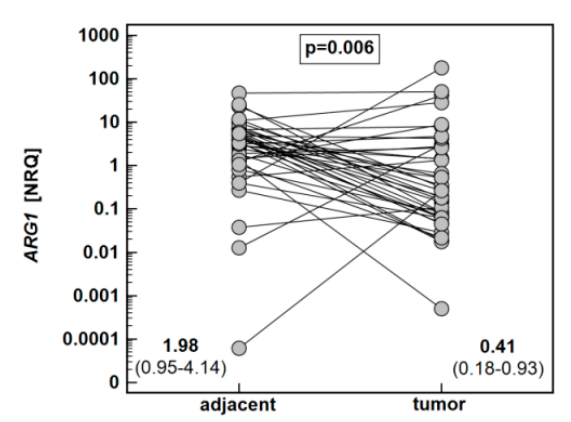

(a)

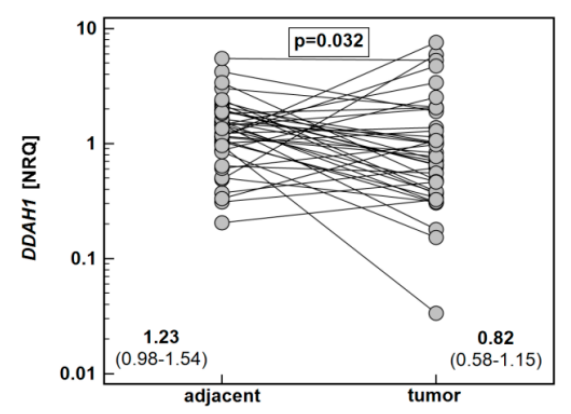

(c)

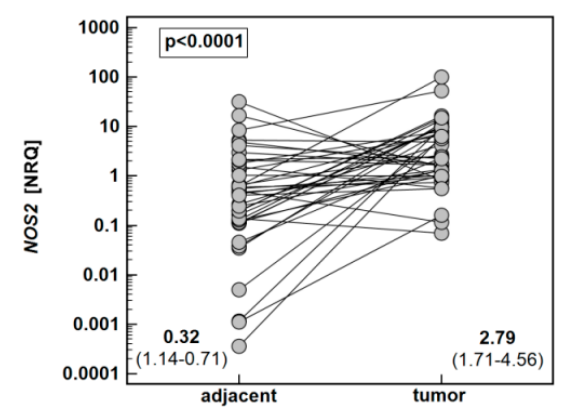

(e)

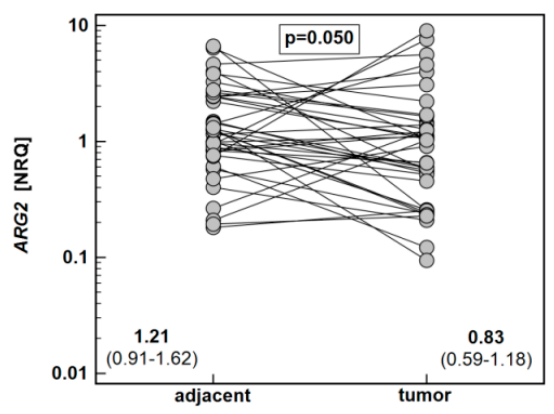

(b)

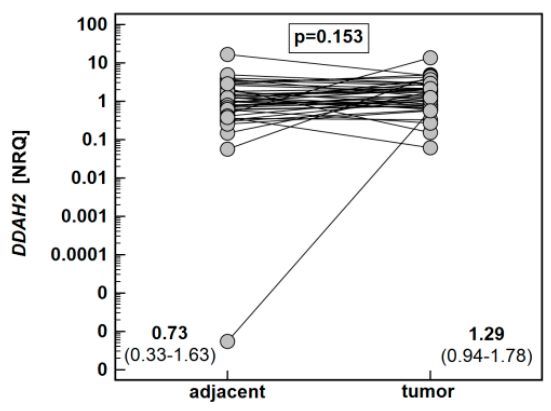

(d)

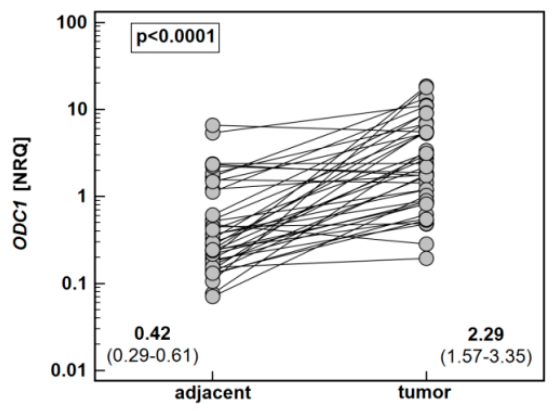

(f)

Figure 6. Cont. 


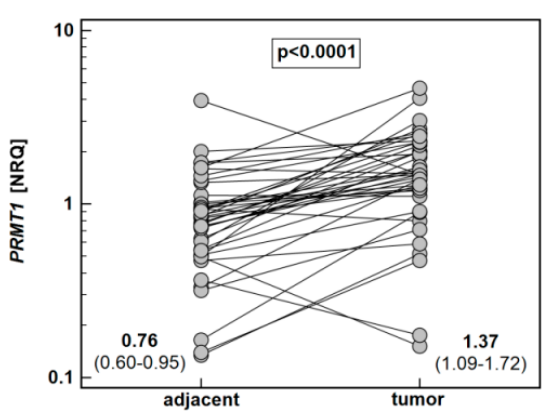

(g)

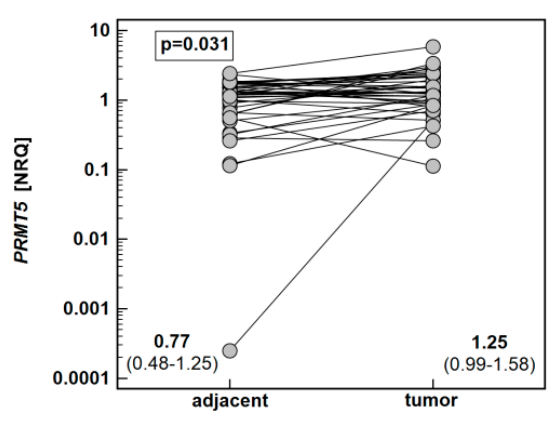

(h)

Figure 6. Tumor and noncancerous tumor-adjacent tissue expression of key enzymes of the L-arginine/NO pathway: (a) ARG1; (b) ARG2; (c) DDAH1; (d) DDAH2; (e) NOS2; (f) ODC1; (g) PRMT1; (h) PRMT5. Data analyzed using a $t$-test for paired samples and presented as means of normalized relative quantities (NRQ) with 95\% confidence interval. ARG, arginase; DDAH, dimethylarginine dimethylaminohydrolase; NOS, nitric oxide synthase; ODC, ornithine decarboxylase; PRMT, protein arginine $\mathrm{N}$-methyltransferase.

\subsubsection{Association between Fold Change in Enzyme Expression and ESCC Pathology}

Potential relationship between fold change in enzyme expression (tumor-to-adjacent) and ESCC pathology was examined (Table 3).

Table 3. Association between expression ratio (tumor-to-adjacent) of L-arginine/NO pathway enzymes and esophageal squamous cell carcinoma pathology.

\begin{tabular}{|c|c|c|c|c|c|c|c|c|}
\hline \multirow{2}{*}{ Pathology } & \multicolumn{8}{|c|}{ Expression Ratio (Tumor-to-Adjacent) } \\
\hline & ARG1 & ARG2 & DDAH1 & DDAH2 & NOS2 & ODC1 & PRMT1 & PRMT5 \\
\hline $\mathrm{TNM}^{1}$ & ns & ns & ns & $\begin{array}{l}\rho=-0.43 \\
p=0.006\end{array}$ & ns & $\begin{array}{l}\rho=-0.46 \\
p=0.003\end{array}$ & ns & $\begin{array}{l}\rho=-0.33 \\
p=0.039\end{array}$ \\
\hline $\mathrm{T}^{1}$ & ns & ns & ns & $\begin{array}{l}\rho=-0.31 \\
p=0.051\end{array}$ & ns & $\begin{array}{l}\rho=-0.39 \\
p=0.012\end{array}$ & ns & ns \\
\hline $\mathrm{N} 1$ vs. $\mathrm{N}^{2}$ & $\begin{array}{c}0.14 \text { vs. } 0.33 \\
p=0.420\end{array}$ & $\begin{array}{c}0.5 \text { vs. } 0.97 \\
p=0.080\end{array}$ & $\begin{array}{c}0.5 \text { vs. } 0.91 \\
p=0.110\end{array}$ & $\begin{array}{c}0.94 \text { vs. } 3.6 \\
p=0.092\end{array}$ & $\begin{array}{c}4.1 \text { vs. } 20.3 \\
p=0.090\end{array}$ & $\begin{array}{c}3.8 \text { vs. } 8.1 \\
p=0.079\end{array}$ & $\begin{array}{c}1.5 \mathrm{vs} . \\
2.3 \\
p=0.039\end{array}$ & $\begin{array}{l}1.1 \text { vs. } 2.5 \\
p=0.056\end{array}$ \\
\hline $\mathrm{M} 1$ vs. $\mathrm{M}^{2}$ & $\begin{array}{c}0.07 \text { vs. } 0.24 \\
p=0.465\end{array}$ & $\begin{array}{c}0.69 \text { vs. } 0.68 \\
p=0.987\end{array}$ & $\begin{array}{c}0.46 \text { vs. } 0.7 \\
p=0.474\end{array}$ & $\begin{array}{l}0.74 \text { vs. } 2 \\
p=0.408\end{array}$ & $\begin{array}{c}21.1 \text { vs. } 7.7 \\
p=0.487\end{array}$ & $\begin{array}{c}1.6 \text { vs. } 6.5, \\
p=0.032\end{array}$ & $\begin{array}{l}2 \text { vs. } 1.8 \\
p=0.788\end{array}$ & $\begin{array}{c}1.3 \text { vs. } 1.7, \\
p=0.671\end{array}$ \\
\hline
\end{tabular}

1 , Data presented as Spearman rank correlation coefficient rho $(\rho){ }^{2}$, data presented as mean expression ratio (tumor-to adjacent) in patients with $n \geq 1$ cancers as compared to patients with N0 cancers or patients with M1 cancers as compared to patients with M0 cancers. TNM, tumor-node-metastasis cancer staging system; T, depth of primary tumor invasion; N, lymph node metastases; M, distant metastases; ARG, arginase; DDAH, dimethylarginine dimethylaminohydrolase; NOS, nitric oxide synthase; ODC, ornithine decarboxylase; PRMT, protein arginine $\mathrm{N}$-methyltransferase; ns, no significant association or tendency $(p>0.1)$.

Only the fold change in DDAH2, ODC1, and PRMT5 expression differed significantly with overall TNM stage, with tumor-to-adjacent ratio decreasing in a stepwise manner along with increasing stage. The same pattern was present for an association between depth of tumor invasion (T) and fold change in DDAH2 and ODC1. Fold change in ARG2 (by 1.9-fold), DDAH2 (by 3.8-fold), NOS2 (by 5.0-fold), ODC1 (by 2.2-fold), and PRMT5 (by 2.3-fold) tended to decrease, and that of PRMT1 was significantly lower (by 1.6-fold) in cancers metastasizing into lymph nodes $(\mathrm{N} \geq 1)$. Fold change in ODC1 was significantly lower (by 4.1-fold) in cancers metastasizing to distant organs as well (Table 3).

We investigated whether inverse relationship between expression ratios (tumor-to-adjacent) and cancer advancement results from changes in gene expression in tumor (Table 4) or/and in adjacent noncancerous tissue (Table 5). 
Table 4. Association between relative expression of L-arginine/NO pathway enzymes in tumors and esophageal squamous cell carcinoma pathology.

\begin{tabular}{|c|c|c|c|c|c|c|c|c|}
\hline \multirow{2}{*}{ Pathology } & \multicolumn{8}{|c|}{ Relative Gene Expression in Tumors (NRQ) } \\
\hline & ARG1 & ARG2 & DDAH1 & DDAH2 & NOS2 & ODC1 & PRMT1 & PRMT5 \\
\hline $\mathrm{TNM}^{1}$ & ns & ns & ns & ns & ns & $\begin{array}{l}\rho=-0.28 \\
p=0.082\end{array}$ & ns & ns \\
\hline $\mathrm{T}^{1}$ & ns & ns & ns & ns & ns & ns & ns & ns \\
\hline $\begin{array}{l}\text { N1 vs. } \\
\text { N0 }^{2}\end{array}$ & $\begin{array}{c}0.39 \text { vs. } 0.42 \\
p=0.909\end{array}$ & $\begin{array}{c}0.74 \text { vs. } 0.94 \\
p=0.503\end{array}$ & $\begin{array}{c}0.63 \text { vs. } 1.1 \\
p=0.119\end{array}$ & $\begin{array}{c}1.1 \text { vs. } 1.6 \\
p=0.239\end{array}$ & $\begin{array}{c}2.3 \text { vs. } 3.5 \\
p=0.344\end{array}$ & $\begin{array}{l}2 \text { vs. } 2.7 \\
p=0.468\end{array}$ & $\begin{array}{l}1.2 \text { vs. } 1.6 \\
p=0.220\end{array}$ & $\begin{array}{c}1.1 \text { vs. } 1.4, \\
p=0.383\end{array}$ \\
\hline $\begin{array}{l}\text { M1 vs. } \\
\text { M0 }\end{array}$ & $\begin{array}{c}0.28 \text { vs. } 0.43 \\
p=0.743\end{array}$ & $\begin{array}{l}1.1 \text { vs. } 0.8 \\
p=0.568\end{array}$ & $\begin{array}{c}0.95 \text { vs. } 0.8 \\
p=0.743\end{array}$ & $\begin{array}{c}1.2 \text { vs. } 1.3 \\
p=0.895\end{array}$ & $\begin{array}{c}11.6 \text { vs. } 2.3 \\
p=0.024\end{array}$ & $\begin{array}{c}0.76 \text { vs. } 2.7 \\
p=0.023\end{array}$ & $\begin{array}{c}1.7 \text { vs. } 1.3 \\
p=0.444\end{array}$ & $\begin{array}{c}1.6 \text { vs. } 1.2 \\
p=0.479\end{array}$ \\
\hline \multicolumn{9}{|c|}{$\begin{array}{l}{ }^{1} \text { Data presented as Spearman rank correlation coefficient rho }(\rho){ }^{2} \text {, data presented as mean relative gene expression } \\
(\mathrm{NRQ}) \text { in tumors in patients with } n \geq 1 \text { cancers as compared to patients with N0 cancers or patients with M1 } \\
\text { cancers as compared to patients with M0 cancers. TNM, tumor-node-metastasis cancer staging system; T, depth of } \\
\text { primary tumor invasion; N, lymph node metastases; M, distant metastases; ARG, arginase; DDAH, dimethylarginine } \\
\text { dimethylaminohydrolase; NOS, nitric oxide synthase; ODC, ornithine decarboxylase; PRMT, protein arginine } \\
\text { N-methyltransferase; ns, no significant association or tendency }(p>0.1) \text {. }\end{array}$} \\
\hline
\end{tabular}

Table 5. Association between relative expression of L-arginine/NO pathway enzymes in noncancerous tumor-adjacent tissue and esophageal squamous cell carcinoma pathology.

\begin{tabular}{|c|c|c|c|c|c|c|c|c|}
\hline \multirow{2}{*}{ Pathology } & \multicolumn{8}{|c|}{ Relative Gene Expression in Noncancerous Tumor Adjacent Tissue (NRQ) } \\
\hline & ARG1 & ARG2 & DDAH1 & DDAH2 & NOS2 & ODC1 & PRMT1 & PRMT5 \\
\hline $\mathrm{TNM}^{1}$ & ns & $\begin{array}{l}\rho=0.34 \\
p=0.034\end{array}$ & ns & $\begin{array}{l}\rho=0.28 \\
p=0.084\end{array}$ & ns & $\begin{array}{l}\rho=0.30 \\
p=0.061\end{array}$ & ns & ns \\
\hline $\mathrm{T}^{1}$ & ns & $\begin{array}{l}\rho=0.29 \\
p=0.069\end{array}$ & ns & ns & ns & ns & ns & ns \\
\hline $\mathrm{N} 1$ vs. $\mathrm{N}^{2}$ & $\begin{array}{l}2.9 \text { vs. } 1.3 \\
p=0.300\end{array}$ & $\begin{array}{c}1.5 \text { vs. } 0.97 \\
p=0.143\end{array}$ & $\begin{array}{l}1.3 \text { vs. } 1.2 \\
p=0.797\end{array}$ & $\begin{array}{c}1.1 \text { vs. } 0.44 \\
p=0.238\end{array}$ & $\begin{array}{c}0.55 \text { vs. } 0.18 \\
p=0.145\end{array}$ & $\begin{array}{c}0.54 \text { vs. } 0.33 \\
p=0.185\end{array}$ & $\begin{array}{c}0.82 \text { vs. } 0.69 \\
p=0.442\end{array}$ & $\begin{array}{l}1 \text { vs. } 0.56 \\
p=0.200\end{array}$ \\
\hline
\end{tabular}

${ }^{1}$, Data presented as Spearman rank correlation coefficient rho $(\rho){ }^{2}$, data presented as mean relative gene expression (NRQ) in noncancerous tumor-adjacent tissue in patients with $n \geq 1$ cancers as compared to patients with N0 cancers or in patients with M1 cancers as compared to patients with M0 cancers. TNM, tumor-node-metastasis cancer staging system; $\mathrm{T}$, depth of primary tumor invasion; $\mathrm{N}$, lymph node metastases; $\mathrm{M}$, distant metastases; ARG, arginase; DDAH, dimethylarginine dimethylaminohydrolase; NOS, nitric oxide synthase; ODC, ornithine decarboxylase; PRMT, protein arginine N-methyltransferase; ns, no significant association or tendency $(p>0.1)$.

This analysis revealed that a negative correlation between $O D C 1$ expression ratio and TNM resulted from the concomitant downregulation of enzyme expression in tumors along with the increasing stage (Table 4) and its upregulation in noncancerous adjacent tissue (Table 5). The expression of $D D A H 2$ did not change in tumors but tended to increase along with increasing TNM in the adjacent tissue (Table 5), contributing to a significantly negative correlation between expression rate and stage (Table 3). Additionally, ARG2 expression in adjacent tissue tended to increase with advancing disease (Table 5).

The clear tendency of expression ratios being lower in $\mathrm{N} \geq 1$ than $\mathrm{N} 0$ cancers also seem to result from combined slightly lower enzyme expression in tumors (Table 4) and higher in adjacent noncancerous tissue (Table 5) derived from of $\mathrm{N} \geq 1$ patients.

Only lower ODC1 expression ratio in M1 than M0 cancers (Table 3) resulted from significantly lower gene expression in tumors from M1 patients (by 3.5-fold) (Table 4). The presence of distant metastases was, in turn, associated with significantly higher expression of NOS2 in tumors (by 5.1-fold) (Table 4). It was also associated with a tendency towards a higher expression of ARG1 and DDAH1 in noncancerous tumor-adjacent tissue (Table 5).

\subsubsection{Interrelationship between Local Expression Levels of L-arginine/NO Pathway Enzymes}

Correlation patterns in the enzyme expression in tumor (Table 6) and noncancerous adjacent tissue were compared (Table 7). In tumor tissue, both $A R G$ s were correlated positively with both $D D A H s$, while in adjacent tissue, ARG1 was correlated solely with DDAH1. In tumors, NOS2 correlated with both PRMTs, while in adjacent tissue, only with PRMT1 and additionally with ODC1. In tumors, 
ODC1 correlated with both $A R G$ s, DDAH2, and PRMT5, while in adjacent tissue, solely with ARG2 isoenzyme, with DDAH2, NOS2, and both PRMTs. The expression pattern for DDAH1 was similar, although the associations with ARG1 and PRMTs were weaker in tumors. In turn, DDAH2 in tumors was positively correlated with all genes, while in adjacent tissue, there was no correlation with $A R G 1$ and NOS2. The expression of PRMT5 in tumors correlated with NOS2 but not ARG1, while in adjacent tissue, with ARG1 but not NOS2. The expression of PRMT1 in tumors did not correlate with ODC1, while the association was present in tumor-adjacent tissue.

Table 6. Interrelationship between expression levels of L-arginine/NO pathway enzymes in tumors.

\begin{tabular}{ccccccccc}
\hline Gene & ARG1 & ARG2 & DDAH1 & DDAH2 & NOS2 & ODC1 & PRMT1 & PRMT5 \\
\hline ARG1 & $0.40^{1}$ & $0.36^{1}$ & $0.53^{3}$ & - & $0.51^{3}$ & - & - \\
ARG2 & & & $0.43^{2}$ & $0.46^{2}$ & - & $0.47^{2}$ & $0.34^{1}$ & $0.58^{3}$ \\
DDAH1 & & & & $0.62^{3}$ & - & - & $0.48^{2}$ & $0.32^{1}$ \\
DDAH2 & & & & & $0.27^{4}$ & $0.38^{1}$ & $0.74^{3}$ & $0.57^{3}$ \\
NOS2 & & & & & & - & $0.42^{2}$ & $0.47^{2}$ \\
ODC1 & & & & & & & - & $0.46^{2}$ \\
PRMT1 & & & & & & & $0.63^{3}$ \\
\hline
\end{tabular}

Data presented as Spearman rank correlation coefficient rho ( $\rho)$. ARG, arginase; DDAH, dimethylarginine dimethylaminohydrolase; NOS, nitric oxide synthase; ODC, ornithine decarboxylase; PRMT, protein arginine $\mathrm{N}$-methyltransferase; ${ }^{1}, p<0.05{ }^{2}, p<0.01{ }^{3}, p<0.001 ;{ }^{4}, 0.05<p<0.1 ;-$, no significant association or tendency $(p>0.1)$.

Table 7. Interrelationship between expression levels of L-arginine/NO pathway enzymes noncancerous tumor-adjacent tissue.

\begin{tabular}{ccccccccc}
\hline Gene & ARG1 & ARG2 & DDAH1 & DDAH2 & NOS2 & ODC1 & PRMT1 & PRMT5 \\
\hline ARG1 & $0.43^{2}$ & $0.50^{3}$ & - & - & - & - & $0.47^{2}$ \\
ARG2 & & & $0.45^{2}$ & $0.53^{3}$ & - & $0.59^{3}$ & $0.60^{3}$ & $0.63^{3}$ \\
DDAH1 & & & & $0.51^{3}$ & - & - & $0.66^{3}$ & $0.66^{3}$ \\
DDAH2 & & & & & - & $0.55^{3}$ & $0.69^{3}$ & $0.63^{3}$ \\
NOS2 & & & & & & $0.55^{3}$ & $0.33^{1}$ & - \\
ODC1 & & & & & & $0.50^{3}$ & $0.36^{1}$ \\
PRMT1 & & & & & & & $0.87^{3}$ \\
\hline
\end{tabular}

Data presented as Spearman rank correlation coefficient rho ( $\rho$ ). ARG, arginase; DDAH, dimethylarginine dimethylaminohydrolase; NOS, nitric oxide synthase; ODC, ornithine decarboxylase; PRMT, protein arginine N-methyltransferase; ${ }^{1}, p<0.05 ;^{2}, p<0.01 ;^{3}, p<0.001 ;-$, no significant association or tendency $(p>0.1)$.

2.2.4. Correlation between Local Expression Levels of L-arginine/NO Pathway Enzymes and Circulating Cytokines, Chemokines, and Growth Factors as Well as Systemic Concentrations of Pathway Metabolites

The correlation pattern between enzyme expression in tumor (Table 8) and noncancerous tumor-adjacent tissue (Table 9) and systemic concentrations of cytokines, chemokines, and growth factors was examined $(n=36)$. There was a negative correlation between PRMT1 expression and ADMA in tumors. Also, ARG1 tended to positively correlate with ADMA and arginine and ARG2 with citrulline and SDMA. Ornithine negatively correlated with DDAH1 (Table 8). In noncancerous tissue, ADMA tended to correlate with ARG1 (Table 9).

Regarding circulating cytokines, ARG1 in tumors positively correlated with HGF and IL-18 and ARG2 with SDF-1 $\alpha$. DDAH1 displayed a negative correlation with FGF2, while DDAH2 did not show any significant associations. NOS2 positively correlated with IL-4, IL-5, and IL-6 and ODC1 with MCP-1. No significant associations could be observed for PRMTs (Table 8).

In noncancerous tissue, ARG1 was inversely related to HGF and IL-2R $\alpha$ and ARG2 positively with MIP-1 $\beta$. DDAH2 positively correlated with IL-9, IP-10, and SCGF $\beta$, NOS2 with IL-3, IL-9, and LIF, and ODC1 with IL-18, LIF, MIP-1 $\beta$, RANTES, and SCF. Both PRMTs positively correlated with MIP-1 $\beta$. In addition, PRMT5correlated with IL-5 and IL-7 (Table 9). 
Table 8. Association between relative expression of L-arginine/NO pathway enzymes in tumors and circulating cytokines, chemokines, and growth factors as well as systemic concentrations of pathway metabolites.

\begin{tabular}{|c|c|c|c|c|c|c|c|c|}
\hline & $A R G 1$ & $A R G 2$ & DDAH1 & $D D A H 2$ & NOS2 & ODC1 & PRMT1 & PRMT5 \\
\hline ADMA & $0.29^{3}$ & - & - & - & - & - & $-0.49^{2}$ & - \\
\hline Arg & $0.29^{3}$ & - & - & - & - & - & - & - \\
\hline Cit & - & $0.29^{3}$ & - & - & - & - & - & - \\
\hline SDMA & - & $0.30^{3}$ & - & - & - & - & - & - \\
\hline Orn & - & - & $-0.39^{1}$ & - & - & - & - & - \\
\hline FGF2 & - & - & $-0.39^{1}$ & - & - & - & - & - \\
\hline HGF & $0.40^{1}$ & - & - & - & - & - & - & - \\
\hline G-CSF & - & - & - & - & $0.29^{3}$ & - & - & - \\
\hline IL-3 & $0.29^{3}$ & $0.30^{3}$ & - & - & - & - & - & - \\
\hline IL-4 & - & - & - & - & $0.44^{2}$ & - & - & - \\
\hline IL-5 & - & - & - & - & $0.41^{1}$ & - & - & $0.29^{3}$ \\
\hline IL-6 & - & - & - & - & $0.41^{1}$ & - & - & $0.31^{3}$ \\
\hline IL-7 & - & - & - & - & - & - & - & - \\
\hline IL-8 & - & - & - & - & $0.31^{3}$ & - & - & - \\
\hline IL-16 & - & $0.29^{3}$ & - & - & - & - & - & - \\
\hline IL-17 & - & $-0.29^{3}$ & - & - & - & - & - & - \\
\hline IL-18 & $0.39^{1}$ & - & - & - & - & - & - & - \\
\hline $\mathrm{IFN} \gamma$ & - & - & - & - & $0.31^{3}$ & - & - & - \\
\hline IFN $\alpha 2$ & - & - & - & - & - & $0.31^{3}$ & - & - \\
\hline MCP-1 & - & - & - & - & - & $0.35^{1}$ & - & - \\
\hline SDF-1 $\alpha$ & - & $0.34^{1}$ & - & - & - & - & - & - \\
\hline TRAIL & - & $0.32^{3}$ & - & - & - & - & - & - \\
\hline VEGF-A & - & $-0.31^{3}$ & - & - & - & - & - & - \\
\hline
\end{tabular}

Data presented as Spearman rank correlation coefficient rho $(\rho) ;{ }^{1}, p<0.05{ }^{2}, p<0.01{ }^{3}, 0.05<p<0.1 ;-$, no significant association or tendency $(p>0.1)$. ARG, arginase; DDAH, dimethylarginine dimethylaminohydrolase; NOS, nitric oxide synthase; ODC, ornithine decarboxylase; PRMT, protein arginine N-methyltransferase; ADMA, asymmetric dimethylarginine; Arg, arginine; Cit, citrulline; SDMA, symmetric dimethylarginine; Orn, ornithine; FGF2, fibroblast growth factor $\beta$; G-CSF, granulocyte colony-stimulating factor; HGF, hepatocyte growth factor; IFN, interferon; IL, interleukin; MCP-1, monocyte chemoattractant protein 1 ; SDF- $1 \alpha$, stromal cell-derived factor $1 \alpha$; TRAIL, tumor necrosis factor (TNF)-related apoptosis inducing ligand; VEGF-A, vascular endothelial growth factor A.

Table 9. Association between relative expression of L-arginine/NO pathway enzymes in noncancerous tumor-adjacent tissue and circulating cytokines, chemokines, and growth factors as well as systemic concentrations of pathway metabolites.

\begin{tabular}{ccccccccc}
\hline & ARG1 & ARG2 & DDAH1 & DDAH2 & NOS2 & ODC1 & PRMT1 & PRMT5 \\
\hline ADMA & 0.294 & - & - & - & - & - & - & - \\
FGF2 & -0.294 & - & - & - & - & - & - & - \\
G-CSF & - & $-0.28^{4}$ & - & - & - & - & - & - \\
GM-CSF & -0.294 & - & - & - & - & - & - & - \\
GRO $\alpha$ & -0.324 & - & - & - & - & - & - & - \\
HGF & -0.391 & - & - & - & - & - & - & - \\
IL-3 & - & - & - & - & $0.37^{1}$ & $0.30^{4}$ & - & - \\
IL-4 & - & - & - & - & - & - & $0.31^{4}$ & $0.32^{4}$ \\
IL-5 & - & - & - & $0.33^{4}$ & - & - & 0.33 & $0.33^{1}$ \\
IL-6 & - & - & - & - & - & - & - & - \\
IL-7 & - & - & - & - & - & - & $0.33^{4}$ & $0.37^{1}$ \\
IL-8 & - & - & - & - & - & - & $0.30^{4}$ & - \\
IL-9 & - & - & - & 0.34 & $0.40^{1}$ & $0.33^{4}$ & - & - \\
IL-13 & $-0.33^{4}$ & - & - & - & - & - & - & - \\
IL-15 & - & - & - & - & 0.29 & - & - & - \\
IL-16 & $-0.33^{4}$ & - & - & - & - & $0.30^{4}$ & - & - \\
IL-18 & - & - & - & - & - & $0.37^{1}$ & - & - \\
\hline
\end{tabular}


Table 9. Cont.

\begin{tabular}{ccccccccc}
\hline & ARG1 & ARG2 & DDAH1 & DDAH2 & NOS2 & ODC1 & PRMT1 & PRMT5 \\
\hline IL-2R $\alpha$ & $-0.35^{1}$ & - & - & - & - & $0.29^{4}$ & - & - \\
IFN $\alpha 2$ & - & - & - & - & - & $0.32^{4}$ & - & - \\
IP-10 & - & - & - & $0.34^{1}$ & - & - & - & - \\
LIF & -0.294 & - & - & $0.45^{2}$ & $0.38^{1}$ & $0.53^{3}$ & $0.28^{4}$ & - \\
MCP-1 & - & - & - & - & $0.30^{4}$ & - & - & - \\
MIP-1 $\beta$ & - & $0.36^{1}$ & - & $0.30^{4}$ & - & $0.38^{1}$ & $0.37^{1}$ & $0.38^{1}$ \\
RANTES & - & - & $-0.30^{4}$ & - & $0.28^{4}$ & $0.45^{2}$ & - & - \\
SCGF $\beta$ & - & - & - & $0.34^{1}$ & - & - & 0.294 & - \\
SDF-1 $\alpha$ & - & - & - & - & $0.29^{4}$ & - & - & - \\
SCF & - & - & - & - & - & $0.41^{1}$ & - & - \\
TNF $\alpha$ & - & - & - & $0.28^{4}$ & - & - & $0.30^{4}$ & - \\
TRAIL & - & - & - & - & - & $0.33^{4}$ & - & -
\end{tabular}

Data presented as Spearman rank correlation coefficient rho $(\rho) ;{ }^{1}, p<0.05 ;{ }^{2}, p<0.01 ;{ }^{3}, p<0.001 ;{ }^{4}, 0.05<p<0.1$; - , no significant association or tendency $(p>0.1)$. ARG, arginase; DDAH, dimethylarginine dimethylaminohydrolase; NOS, nitric oxide synthase; ODC, ornithine decarboxylase; PRMT, protein arginine N-methyltransferase; ADMA, asymmetric dimethylarginine; FGF2, fibroblast growth factor $\beta$; G-CSF, granulocyte colony-stimulating factor; GM-CSF, granulocyte-macrophage colony-stimulating factor; GROa, growth-regulated alpha protein (CXCL1); HGF, hepatocyte growth factor; IFN, interferon; IL, interleukin; IL-2R $\alpha$, interleukin 2 receptor subunit $\alpha$; IP-10, interferon gamma-induced protein 10 (CXCL10); LIF, leukemia inhibitory factor; MCP-1, monocyte chemoattractant protein 1; MIP, macrophage inflammatory protein; RANTES, regulated on activation, normal T-cell expressed and secreted (CCL5); SCF, stem cell factor; SCGF $\beta$, stem cell growth factor $\beta$; SDF- $1 \alpha$, stromal cell-derived factor $1 \alpha$; TNF $\alpha$, tumor necrosis factor $\alpha$; TRAIL, tumor necrosis factor (TNF)-related apoptosis inducing ligand.

\section{Discussion}

In the era of precision medicine, metabolic reprogramming of cancer cells is considered a promising source of potential biomarkers and novel molecular targets for antineoplastic strategies [15]. In this respect, the L-arginine/NO pathway becomes an area of active investigation. Its focus is shared between the arginine/ornithine/polyamines rout, the interest in which has recently rekindled, and arginine methylation, its methylated derivatives, and their metabolism, an understudied topic in cancer context. The present study provides a comprehensive overview of pathway status in ESCC, including local enzyme expression and systemic metabolites, with reference to a broad spectrum of inflammatory, immune, and angiogenic mediators. Corroborating our own preliminary observations [6] as well as findings of others [16,17], ODC1 expression in ESCC tumors was markedly upregulated as compared to adjacent noncancerous tissue. As a rate-limiting enzyme of the polyamine pathway and a down-stream target of c-Myc, ODC is implicated in facilitating tumor growth [18]. Moreover, its overexpression can induce neoplastic transformation, making ODC1 an oncogene [19]. Accordingly, $O D C 1$ expression in the colon is upregulated in conditions associated with increased risk of cancer [8]. In turn, the enzyme inhibitors used as chemoprevention, alone or in combination with nonsteroidal anti-inflammatory drugs, have shown promising results in animal models of CRC [20] as well as in clinical trials $[18,21]$. They reduced the number and size of tumors in test animals or prevented formation of sporadic adenomas, respectively. The enzyme has recently been shown to promote ESCC as well. It induces cell proliferation and survival, as the gene silencing or enzyme inhibition with the substrate analogue, difluoromethylornithine, results in cell arrest in the G2/M phase and triggers apoptosis [17]. The advocated enzyme involvement in the initial phases of carcinogenesis would explain a significant enzyme upregulation in tumors and yet a negative correlation of expression rate with ESCC advancement observed here. However, He et al. [17] reported ODC protein to be more pronouncedly expressed in samples obtained from patients with stage III or N1 cancers than with stage II or N0. When ODC1 expression patterns were inspected more thoroughly, we found that $O D C 1$ expression in patients with more advanced cancers decreased in tumors but increased in adjacent tissue. As the changes affect both normal tissue and the tumor, and they occur in opposite directions, unsurprisingly, systemic ornithine did not differ with respect to ESCC stage. 
Likewise, a negative correlation between the disease advancement, particularly lymph node involvement, was observed for DDAHs and PRMTs. Similarly to ODC1, it resulted from gene downregulation in tumors with concomitant upregulation in tumor-adjacent noncancerous tissue. The phenomenon of so-called "tumor molecular margin", describing alterations in molecular landscape in the tissue surrounding tumor, is increasingly recognized and has previously been documented also in ESCC [22]. This phenomenon is of clinical relevance as it is held responsible, at least in part, for synchronous tumors and cancer recurrence following treatment [23,24]. Moreover, it is considered to better represent dysregulations leading to neoplastic transformation than changes encountered in already transformed tissue. As such, studying the tumor molecular margin is deemed better suited to aid the discovery of potential targets for chemoprevention [24]. Regarding L-arginine/NO pathway enzymes, our group showed DDAHs and PRMTs in CRC to be apparently downregulated, as their relative expression was lower in tumors than in adjacent tissue, while they were in fact upregulated in both. There were no normal esophageal mucosa samples available for comparison in the present study, but the observation on adjacent tissue not being "inert" but displaying an increasing enzyme expression with advancing disease seems to indicate that ESCC might be like CRC in this respect. Still, a lack of control mucosa samples from healthy individuals should be recognized as a limitation of the current study.

The analysis of RNA-seq expression data gathered by The Cancer Genome Atlas (TCGA) Research Network and the Genotype-Tissue Expression (GTEx) project indicated DDAH1 upregulation in ESCC [25], although confirming individual studies, analyzing DDAH1 association with reference to ESCC pathology, seem to be missing. The DDAH2 status, as well as the precise role of either isoform in cancer, remains largely unknown. Here, $D D A H 1$ was slightly downregulated in tumors, and DDAH2 did not show significant difference as compared to the surrounding tissue. Their expression levels were interrelated, but there was variation in their correlation pattern with other genes as well as circulating cytokines, supporting the notion that neither their distribution nor function is completely overlapping [25]. Both enzymes catabolize ADMA, but their spatial transcriptional patterns differ and they may be altered in cancer in a different, sometimes opposing, manner [25]. The overexpression of DDAH1 and DDAH2 is linked with the promotion of angiogenesis by the indirect stimulation of VEGF-A expression and NO synthesis, via degrading NOS inhibitor-ADMA. Consequently, their targeting is viewed as an emerging anticancer strategy $[25,26]$. However, neither DDAH1 nor $D D A H 2$ correlated with circulating VEGF-A in the present study. On the contrary, DDAH1 in tumors exhibited a negative correlation with another angiogenic factor, FGF2, and DDAH2 in tumor-adjacent tissue-a positive association with an angiostatic IP-10. Moreover, the expression of DDAH2 only tended to weakly correlate with NOS2 in tumors, although in prostatic cancer cell lines, its expression was accompanied by the upregulation of iNOS and VEGF-A [27]. As mentioned, ADMA is considered to inhibit angiogenesis, but its role in cancer is unclear. Extensively investigated in cardiometabolic diseases [28], it has been understudied in cancer. However, limited evidence indicates that ADMA accumulate in tumor and surrounding tissue [29] and may support tumor growth by protecting cancer cells from nutritional stress and drug-induced death [30]. Here, consistently with a cancer-promoting role, its systemic concentrations were elevated. Moreover, ADMA levels positively correlated with immune mediators known to support cancer development, the most strongly with GRO $\alpha$ (CXCL1), the cytokine released from tumors as well as tumor-associated macrophages and implicated in the recruitment of tumor-associated neutrophils [31] and promotion of metastasis [32], respectively, and associated with poor overall survival [33].

The expression of various PRMT isoenzymes in cancer is also largely unknown, but gaining attention as potential targets for chemoprevention [34,35]. Their targeting is also investigated as potential strategy for overcoming cancer chemoresistance [36]. It becomes increasingly apparent that the role of PRMTs is not limited to NO synthesis. The enzymes have been implicated in the global regulation of RNA splicing and translation [37]. Both PRMT1 and PRMT5 support tumor growth and are, therefore, overexpressed in a number of cancers [34]. Corroborating our observation, the expression of 
PRMT1 is upregulated in ESCC [38,39] and head and neck tumors [40]. Mechanistically, it facilitates cell proliferation and migration of oral and esophageal squamous cell carcinoma cells [38,40]. In addition, Zhao et al. [39] showed PRMT1 to be preferentially expressed in esophageal tumor initiating cells and function to enhance the self-renewal features, tumorigenicity, and chemoresistance of ESCC. The role of PRMT5 in cancer is even more poorly understood. Mostly oncogenic, owing to promoting cancer cell proliferation and migration, in breast cancer it prevents metastasis, while data regarding prostate cancer are contradictory (reviewed in [41]). Only recently, PRMT5 has been shown to regulate Hsp90A, a known cancer-related chaperone providing protection for a number of oncoproteins [42]. There seems to be no previous reports on PRMT5 expression in ESCC. We found it upregulated in tumors as compared to adjacent tissue. In cancers metastasizing to lymph nodes, its expression increased in tumor adjacent tissue. The expression of PRMT5 was tightly associated with that of PRMT1, more so in adjacent tissue than tumors. Of the other pathway enzymes, $P R M T 5$ expression was associated closely with that of $A R G 2$ and DDAHs, in tumors more so with DDAH2 than DDAH1. In turn, a correlation with NOS2 could be observed in ESCC tumors. Reflecting enzyme ability to induce expression of proinflammatory genes [43], both PRMTs were positively correlated with circulating MIP-1 $\beta$.

Arginases compete with NOS enzymes for arginine and, as NOS activity is considered cancer-promoting, strategies based on upregulating endogenous arginase activity or introduction of exogenous arginine-consuming enzymes are currently being tested [11,12]. Moreover, arginases synthesize ornithine and, therefore, supply substrates for polyamine biosynthesis [44]. Accordingly, $A R G 2$ expression level, and in tumors also that of $A R G 1$, was positively correlated with $O D C 1$, a key regulatory enzyme of the pathway. However, arginine is necessary for the proper functioning of immune cells, and its depletion is a strategy of immune evasion employed by cancer cells $[11,45,46]$. Moreover, arginase-2 is expressed by immunosuppressive M2 polarized macrophages and dendritic cells as well as myeloid-derived suppressor cells [47]. In the sample set investigated, ARG1 was substantially while $A R G 2$ borderline significantly downregulated in tumors. Consistent with counter-regulatory mechanisms in the ARG/NOS interplay [44], NOS2 was markedly upregulated and ARG1 tended to positively correlate with the systemic concentration of ADMA, a NOS inhibitor. Moreover, NOS2 was the only pathway enzyme clearly expressed at a higher level in metastasizing tumors. In line with its proinflammatory character, NOS2 expression correlated positively with circulating immune and inflammatory mediators, whilst ARG1, a hepatocyte isoform [44], correlated with HGF, positively in tumors but negatively in adjacent tissue. Consistent with this observation, HGF/c-met signaling axis was shown to induce macrophage M2 polarization as its inhibition upregulated NOS2 and other M1 polarization markers and downregulated ARG1 [48]. The expression of ARG2, but not ARG1, has been shown to be upregulated by hypoxia and implicated in mediating hypoxia-induced cancer cell proliferation [49]. Moreover, cancer-associated fibroblasts and tumor-associated M2 macrophages from hypoxic regions overexpress ARG2 as well [50]. In macrophages, HIF-1 $\alpha$ controls iNOS while HIF $2 \alpha$-arginase [51]. Supporting the ARG2 link with hypoxia and angiogenesis, ARG2 expression in evaluated tumors positively correlated with SDF- $1 \alpha$, a hypoxia-induced proangiogenic factor [52], although its relation to VEGF-A tended to be negative.

Cancer-associated upregulation of arginase -1 contributes to a diminished extracellular arginine pool [11]. Here, consistently with decreased ARG1 and ARG2 expression, systemic arginine was elevated. Likewise, the arginine-to-citrulline and ornithine ratio was higher, indicative of increased arginine bioavailability in ESCC. A weak positive correlation between amino acid bioavailability and the disease stage resulted from gradually decreasing citrulline concentration, implying accelerating activity of the arginine-citrulline pathway in parallel with ESCC advancement. Arginine can be regenerated from citrulline by argininosuccinate synthetase (ASL) and argininosuccinate lyase (ASS1), and ASS1 is a rate-limiting enzyme of this pathway [53]. As ASS1 expression, especially leukocyte enzyme, is controlled by inflammatory and immune mediators [53], the systemic citrulline concentration in our patients was tightly but inversely related to their level. The expression of ASS1 is upregulated also by p53, in order to ensure cell survival under genotoxic stress conditions [54]. Still, ASS1 is reported to be 
epigenetically silenced in some cancer types [55], making them sensitive to antineoplastic therapy based on arginine-deprivation. Nonaffected arginine bioavailability, due to the efficient arginine-citrulline recycling pathway demonstrated here, would indicate that ESCC is not a suitable candidate.

Elevated plasma concentrations of arginine, dimethylarginines (pooled ADMA and SDMA), and $\mathrm{N}$-acetylated derivatives of putrescine and ornithine have been observed in children with eosinophilic esophagitis [56]. In line with the implicated close relationship between eosinophils and the pathway metabolites, both $A R G$ s tended to positively correlate with IL-3 in tumors. The expression of $A R G 1$ in adjacent tissue also correlated with other eosinophil-associated cytokines such as IL-13 and GM-CSF and that of NOS2 with IL-5. In addition, ADMA positively correlated with IL-3 and SDMA also with IL-13 and GM-CSF.

Correlation analysis showed that DDAH2, NOS2, and ODC1 expression in normal tissue was positively correlated with circulating LIF. In addition, LIF concentration was correlated also with SDMA and, consistently with a possible positive effect on DDAH2, with DMA. The cytokine is regarded as an oncogene, facilitating the self-renewal of tumor-initiating cells, supporting cancer-associated fibroblasts, and inducing resistance to radio- and chemotherapy [57-59]. It has also been found to hamper anti-PD1 therapy by upregulating MIG in tumor-associated macrophages [60]. Consistently, the ADMA and SDMA concentration in our ESCC patients was correlated with that of MIG as well. Intriguingly, various components of the L-arginine/NO pathway were related to the factors associated with cancer cell renewal. The expression of $O D C 1$ was associated with SCF, as was arginine and, more so, SDMA and DMA concentration. The SCF and its receptor c-Kit (CD117) ensure cancer stem cell viability and self-renewing properties. It might be membrane-bound and expressed in cancer cells or tumor-associated macrophages and cancer-associated fibroblasts, from which a soluble form of SCF can be released [61]. The expression of DDAH2 and systemic SDMA and DMA were, in turn, associated with circulating SCGF $\beta$, a growth factor for primitive hematopoietic progenitor cells, which is overexpressed in cancer by circulating cancer cells [62] and drug-resistant cancer stem cells [63].

Metabolomics is gaining interest as a potential tool in biomarker discovery [64], especially in that it enables the concomitant quantification of a predetermined panel of metabolites. The utility of individual intermediates of the L-arginine/NO pathway as biomarkers for various conditions has repeatedly been demonstrated [56,65-67]. In cancer, the simultaneous quantification of SDMA, citrulline, and DMA proved excellent in detecting CRC, and the changes in the early postoperative period in arginine, ADMA, and SDMA were an accurate marker of surgical complications [7]. In ESCC, however, neither individual metabolites nor a panel consisting of ADMA and Arg/(Cit+Orn) index possessed satisfactory diagnostic power to be of clinical use.

\section{Materials and Methods}

\subsection{Sample Collection}

Biobanked material, collected in the Department of Gastrointestinal and General Surgery of Wroclaw Medical University between 2010 and 2015 (prior the introduction of radiotherapy as a treatment preceding surgery), was used in the present study.

Whole blood was drawn from patients by venipuncture into serum separator tubes following overnight fasting and prior to any treatment. Collected blood was clotted for $30 \mathrm{~min}$ at room temperature and centrifuged (1500 $\mathrm{g}$ for $10 \mathrm{~min}$ at room temperature). Obtained sera were aliquoted and stored at $-45^{\circ} \mathrm{C}$ until examination.

Patient-matched tumor and macroscopically normal mucosa were rinsed with PBS and immersed in RNAlater (Ambion Inc., Austin, TX, USA). Solution-soaked tissue samples were then stored at $-80{ }^{\circ} \mathrm{C}$ until RNA isolation. 


\subsection{Study Population-Metabolomic Analysis}

The study population for metabolomic analysis consisted of 123 patients admitted to the Department of Gastrointestinal and General Surgery of Wroclaw Medical University for the diagnosis and treatment of histologically confirmed $\operatorname{ESCC~(~} n=61$; curative surgery or palliative treatment) or benign esophageal conditions $(n=62)$, including esophagoplasty following esophagectomy $(n=16)$ or thermal burn $(n=1)$, achalasia $(n=25)$, stenosis $(n=2)$, esophageal lipoma $(n=2)$, and Zenker's diverticulum $(n=16)$. Cancer patients underwent a standard diagnostic procedure, including blood work, physical examination, and imaging techniques, such as ultrasonography, computed tomography, and magnetic resonance. Cancers were staged clinically using the 7th edition of the Union for International Cancer Control TNM system. Detailed population characteristics are presented in Table 10.

Table 10. Characteristic of study population: metabolomic cohort.

\begin{tabular}{cccc}
\hline Parameter & Benign & ESCC & $p$-Value \\
\hline$N$ & 62 & 61 & - \\
Sex $(\mathrm{F} / \mathrm{M}), n$ & $26 / 36$ & $24 / 37$ & $0.855^{1}$ \\
Age [y], mean $\pm \mathrm{SD}$ & $61.5 \pm 10.2$ & $60.4 \pm 7.3$ & $0.509^{2}$ \\
TNM $(\mathrm{I} / \mathrm{II} / \mathrm{III} / \mathrm{IV}), n$ & - & $10 / 18 / 14 / 19$ & - \\
$\mathrm{T}(1 / 2 / 3 / 4), n$ & - & $10 / 10 / 21 / 20$ & - \\
$\mathrm{N}(0 / \geq 1), n$ & - & $25 / 36$ & - \\
$\mathrm{M}(0 / 1), n$ & - & $42 / 19$ & - \\
\hline
\end{tabular}

$N$, number of patients; F/M, female-to-male ratio; ESCC, esophageal squamous cell carcinoma; yf, years; $\mathrm{SD}$, standard deviation; TNM, tumor-node-metastasis cancer staging system; T, primary tumor extension; N, lymph node metastasis; $M$, distant metastasis. ${ }^{1}$ Fisher exact test; ${ }^{2}$ Welch test.

\subsection{Study Population-Transcriptomic Analysis}

The study population for transcriptomic analysis consisted of 40 ESCC patients undergoing curative tumor resection in the Department of Gastrointestinal and General Surgery of Wroclaw Medical University. Patients with any severe systemic illness, with gross metastatic disease, or subjected to radio- or chemotherapy were not included. Patients were subjected to standard preoperative evaluation (blood work, physical examination, and imaging techniques, such as ultrasonography, computed tomography, and magnetic resonance). Cancers were staged pathologically using the 7th edition of the Union for International Cancer Control TNM system. In all cases, the resection margins were confirmed to be tumor-free. Detailed population characteristics are depicted in Table 11.

Table 11. Characteristic of study population: transcriptomic cohort.

\begin{tabular}{cc}
\hline Parameter & ESCC \\
\hline$N$ & 40 \\
Sex (F/M), $n$ & $15 / 25$ \\
Age [y], mean \pm SD & $57.9 \pm 6.9$ \\
Stage (I/II/III/IV) & $3 / 12 / 19 / 5$ \\
Primary tumor, T (1/2/3/4) & $2 / 11 / 20 / 7$ \\
Lymph node metastasis, N (no/yes) & $19 / 21$ \\
Distant metastasis, M (no/yes) & $35 / 5$ \\
\hline
\end{tabular}

$N$, number of patients; F/M, female-to-male ratio; ESCC, esophageal squamous cell carcinoma; y, years; SD, standard deviation; TNM, tumor-node-metastasis cancer staging system; T, depth of tumor invasion; N, lymph node metastasis; $\mathrm{M}$, distant metastasis.

\subsection{Ethical Considerations}

The sample collection was approved by the Medical Ethics Committee of Wroclaw Medical University (\#KB 28/2011 and \#KB 784/2012). The study was conducted in accordance with the Helsinki Declaration of 1975, as revised in 1983, and informed consent was obtained from all study participants. 


\subsection{Analytical Methods}

\subsubsection{Metabolomic Analysis}

Chemicals

Benzoyl chloride $(\mathrm{BCl})$, hydrochloride salts of unlabeled dimethylamine (D0-DMA), hexadeuterodimethylamine (D6-DMA, declared as 99 atom \% 2H), L-arginine, SDMA, ADMA, L-citrulline, L-Ornithine monohydrochloride, labeled L-Ornithine hydrochloride (3,3,4,4,5,5-D6-ornithine), and sodium tetraborate were procured from Sigma-Aldrich (Poznan, Poland). Isotope labeled L-arginine: $\mathrm{HCl}$ (D7-arginine, 98\%) and asymmetric dimethylarginine (2,3,3,4,4,5,5-D7-ADMA, 98\%) were obtained from Cambridge Isotope Laboratories (Tewksbury, MA, USA). Methanol, acetonitrile, water, and formic acid were acquired from Merck Millipore (Warsaw, Poland), and leucine-enkephalin was obtained from Waters (Milford, MA, USA).

\section{LC-QTOF-MS Analysis of Selected L-arginine/NO Pathway Metabolites}

The stock solutions of DMA, arginine, ADMA, SDMA, citrulline, ornithine, and isotope labeled standards were prepared in water and stored at $-20^{\circ} \mathrm{C}$. Standard calibration curves were prepared by diluting the stock solutions in water in the following concentration ranges: $3.0-150 \mu \mathrm{M}$ for ornithine, 5.0-250 $\mu \mathrm{M}$ for arginine, 0.05-2.5 $\mu \mathrm{M}$ for ADMA and SDMA, 1.0-50 $\mu \mathrm{M}$ for citrulline, and 0.14-7.0 $\mu \mathrm{M}$ for DMA.

Serum samples and calibration standards were prepared using previously validated and described methods [7,8,68-71]. Analysis of L-arginine/NO pathway metabolites as benzamide derivatives allows for the chromatographic separation of highly polar substances using a reversed phase system with relatively high retention. Importantly, it also enabled the chromatographic separation of ADMA and SDMA. The extraction and derivatization procedure was conducted as follows: $100 \mu \mathrm{L}$ aliquots of the calibration standards or serum were mixed with $10 \mu \mathrm{L}$ internal standard solution (50 $\mu \mathrm{M}$ D6-DMA, $20 \mu \mathrm{M}$ D7-ADMA, $100 \mu \mathrm{M}$ D7-arginine, and $70 \mu \mathrm{M}$ D6- ornithine, respectively) and $50 \mu \mathrm{L}$ borate buffer $\left(0.025 \mathrm{M} \mathrm{Na}_{2} \mathrm{~B}_{4} \mathrm{O}_{7} \cdot 10 \mathrm{H}_{2} \mathrm{O}, 1.77 \mathrm{mM} \mathrm{NaOH}, \mathrm{pH}=9.2\right)$ and vortexed $\left(1 \mathrm{~min}, 25^{\circ} \mathrm{C}\right)$. The samples were derivatized with $10 \% \mathrm{BCl}$ in acetonitrile $(400 \mu \mathrm{L})$ at $25^{\circ} \mathrm{C}$ for $10 \mathrm{~min}$. The mixture was centrifuged at 10,000 RPM for $7 \mathrm{~min}$ in $4{ }^{\circ} \mathrm{C}$. Two microliters of supernatants diluted with water in a 1:5 ratio was injected into an LC system consisting of a Waters nanoACQUITY UPLC and a nanoAcquity HSS T3 column (C18-phase, internal diameter $1 \mathrm{~mm}$, length $50 \mathrm{~mm}$, particle size $1.8 \mu \mathrm{m})$. They were eluted at a flow rate of $0.22 \mathrm{~mL} / \mathrm{min}$ with a linear gradient of $0.1 \%$ formic acid in water (A) and $0.1 \%$ formic acid in methanol (B) performed as follows: $3 \%$ B for $1.5 \mathrm{~min}$, from 3\% to14\% B in $2.0 \mathrm{~min}$, from $14 \%$ to $60 \% \mathrm{~B}$ in $1.5 \mathrm{~min}$, from $60 \%$ to $90 \% \mathrm{~B}$ in $0.5 \mathrm{~min}, 90 \% \mathrm{~B}$ for $1.0 \mathrm{~min}$, and from $90 \%$ to $3 \% \mathrm{~B}$ in $0.10 \mathrm{~min}$; conditioning time was $1.9 \mathrm{~min}$.

The eluates were subjected to analysis by a quadrupole-time-of-flight mass spectrometer (Xevo G2 QTOF MS, Waters) equipped with an electrospray ionization (ESI) source. A voltage of $0.5 \mathrm{kV}$ was applied to the electrospray capillary. The source temperature was at $120^{\circ} \mathrm{C}$, and the desolvation temperature was $450^{\circ} \mathrm{C}$. Nitrogen was used as the desolvation gas $(650 \mathrm{~L} / \mathrm{h})$ and as the cone gas $(65 \mathrm{~L} / \mathrm{h})$. The total ion current was recorded in positive ionization mode, with a scan range from 140 to $600 \mathrm{~m} / \mathrm{z}$. Quantitative analysis was based on extracted ion chromatograms for the following ions (m/z): 341.1501 (for ornithine), 347.1878 (for D6-ornithine), 279.1457 (for arginine), 286.1897 (for D7-arginine), 307.1770 (for ADMA and SDMA), 314.2209 (for D7-ADMA), 263.1090 (for citrulline), 267.1382 (for D4-cytrulline), 150.0919 (for DMA), and 156.1295 (D6-DMA).

\subsubsection{Multiplex Analysis}

In a subset of 45 ESCC patients, the serum concentration of 48 cytokines, chemokines, and growth factors was quantified using the BioPlex 200 platform (Bio-Rad, Herkules, CA, USA), incorporating Luminex $\mathrm{xMAP}^{\circledR}$ technology. This flow cytometry-based method allows for the simultaneous 
quantification of multiple analytes in real-time. It utilizes magnetic microspheres conjugated with monoclonal antibodies and fluorescent reading. Two Bio-Plex Pro $^{\mathrm{TM}}$ Human Cytokine, Chemokine, and Growth Factor Magnetic Bead-Based Assays-Panel I (27-plex) and Panel II (21-plex)—were used. The 27-plex included the following analytes: eotaxin, IL-1 $\beta$, IL-1ra, IL-2, IL-4, IL-5, IL-6, IL-7, IL-8, IL-9, IL-10, IL-12p70, IL-13, IL-15, IL-17, IFN $\gamma$, IP-10, FGF-2, G-CSF, GM-CSF, MCP-1, MIP-1 $\alpha$, MIP-1 $\beta$, PDGF-BB, RANTES, TNF $\alpha$, and VEGF-A. The 21-plex included: IL-1 $\alpha$, IL-2R $\alpha$, IL-3, IL-12p40, IL-16, IL-18, CTACK, GRO- $\alpha$, HGF, IFN- $\alpha 2$, LIF, MCP-3, M-CSF, MIF, MIG, $\beta$-NGF, SCF, SCGF- $\beta$, SDF- $1 \alpha$, TNF- $\beta$, and TRAIL. The concentration of IL- $1 \alpha$, IL-12p40, MCP-3, M-CSF, and TNF- $\beta$ was below the limit of detection in most of the samples, and they were, therefore, excluded from analysis. All analyses were conducted in duplicates and following the manufacturer's instructions. Standard curves were drawn using 5-PL logistic regression, and the data were analyzed using BioPlex Manager 6.0 software.

\subsubsection{Transcriptomic Analysis}

Tissue samples (up to $40 \mathrm{mg}$ ) were homogenized in a Fastprep 24 Homogenizer (MP Biomedical, OH, USA) using lysis buffer (PureLink ${ }^{\mathrm{TM}}$ RNA Mini Kit, Thermo-Fisher Scientific, Waltham, MA, USA) with 2-mercaptoethanol (100:1) (Sigma-Aldrich, St. Luis, MO, USA). Phenol-chloroform extraction was used for RNA isolation and then purified using a PureLink ${ }^{\mathrm{TM}}$ RNA Mini Kit (Thermo-Fisher Scientific), including genomic DNA on-column removal by DNase (PureLink ${ }^{\mathrm{TM}}$ DNase Set, Thermo-Fisher Scientific) treatment. Isolated RNA was quantified using NanoDrop 2000 (Thermo-Fisher Scientific). Its purity was evaluation using absorbance ratios: 260/280 and 260/230 nm, while its integritythe Experion platform, incorporating LabChip microfluidic technology, and Experion RNA StdSens analysis kits (BioRad).

Aliquots of RNA corresponding with $1000 \mathrm{ng}$ per reaction mixture $(20 \mu \mathrm{L})$ were reversely transcribed using a C1000 termocycler (BioRad) and iScript ${ }^{\mathrm{TM}}$ CDNA Synthesis Kit (BioRad) following the manufacturer's protocol.

Quantitative PCR (qPCR) was conducted on a CFX96 Real-Time PCR thermocycler (BioRad) using SsoFast EvaGreen ${ }^{\circledR}$ Supermix (BioRad). The following cycling conditions were applied: $30 \mathrm{~s}$ activation at $95^{\circ} \mathrm{C}, 5 \mathrm{~s}$ denaturation at $95^{\circ} \mathrm{C}$, annealing/extension for $5 \mathrm{~s}$ at $61^{\circ} \mathrm{C}, 45$ cycles, followed by melting step $\left(60-95^{\circ} \mathrm{C}\right.$ with fluorescent reading every $\left.0.5^{\circ} \mathrm{C}\right)$. The reaction mixture consisted of cDNA $\left(2 \mu \mathrm{L}\right.$; diluted 1:5), $2 \times$ SsoFast EvaGreen ${ }^{\circledR}$ Supermix $(10 \mu \mathrm{L}), 10 \mathrm{nM}$ forward and reverse target-specific primers ( $1 \mu \mathrm{L}$ of each), and water up to $20 \mu \mathrm{L}$. Primer specificity was assured in the melting curve analysis and an electrophoresis in a high-resolution agarose (SeaKem LE agarose from Lonza, Basel, Switzerland) in TBE with SYBR Green (Lonza) detection. Primers were synthesized by Genomed (Warsaw, Poland), and their sequences are presented in Table 12.

Table 12. Primers' sequences.

\begin{tabular}{|c|c|c|c|c|}
\hline Gene & Name & Accession No. & Primer sequence $5^{\prime} \rightarrow 3^{\prime}$ & Size $[b p]$ \\
\hline$A R G 1^{1}$ & Arginase-1 & NM_001244438.2 & $\begin{array}{l}\text { F: tcatctgggtggatgctcacac } \\
\text { R: gagaatcctggcacatcgggaa }\end{array}$ & 130 \\
\hline$A R G 2^{1}$ & Arginase-2 & NM_001172.4 & $\begin{array}{l}\text { F: ctggcttgatgaaaaggctctcc } \\
\text { R: tgagcgtggattcactatcaggt }\end{array}$ & 119 \\
\hline NOS2 ${ }^{1}$ & Inducible nitric oxide synthase & NM_000625.4 & $\begin{array}{l}\text { F: gctctacacctccaatgtgacc } \\
\text { R: ctgccgagatttgagcctcatg }\end{array}$ & 136 \\
\hline$O D C 1^{1}$ & Ornithine decarboxylase & NM_002539.3 & $\begin{array}{l}\text { F: ccaaagcagtctgtcgtctcag } \\
\text { R: cagagattgcctgcacgaaggt }\end{array}$ & 162 \\
\hline PRMT1 $^{1}$ & $\begin{array}{c}\text { Arginine } \\
N \text {-methyltransferase-1 }\end{array}$ & NM_001536.5 & $\begin{array}{l}\text { F: tgcggtgaagatcgtcaaagcc } \\
\text { R: ggactcgtagaagaggcagtag }\end{array}$ & 142 \\
\hline PRMT5 $^{1}$ & $\begin{array}{c}\text { Arginine } \\
N \text {-methyltransferase-5 }\end{array}$ & NM_006109.5 & $\begin{array}{l}\text { F: ctagaccgagtaccagaagagg } \\
\text { R: cagcatacagctttatccgccg }\end{array}$ & 136 \\
\hline
\end{tabular}


Table 12. Cont.

\begin{tabular}{ccccc}
\hline Gene & Name & Accession No. & Primer sequence 5' $\rightarrow \mathbf{3}^{\prime}$ & Size [bp] \\
\hline$D D A H 1^{1}$ & $\begin{array}{c}\text { Dimethylarginine } \\
\text { dimethylaminohydrolase-1 }\end{array}$ & NM_012137.4 & $\begin{array}{c}\text { F: atgcagtctccacagtgccagt } \\
\text { R: ttgtcgtagcggtggtcactca }\end{array}$ & 151 \\
\hline$D D A H 2^{1}$ & $\begin{array}{c}\text { Dimethylarginine } \\
\text { dimethylaminohydrolase-2 }\end{array}$ & NM_001303007.2 & $\begin{array}{c}\text { F: ctttcttcgtcctgggttgcct } \\
\text { R: ctccagttctgagcaggacaca }\end{array}$ & 136 \\
\hline$G A P D H^{2}$ & $\begin{array}{c}\text { Glyceraldehyde-3-phosphate } \\
\text { dehydrogenase }\end{array}$ & NM_001256799.3 & $\begin{array}{c}\text { F: tagattattctctgatttggtcgtattgg } \\
\text { R: gctctggaagatggtgatgg }\end{array}$ & 223 \\
\hline
\end{tabular}

${ }^{1}$, primer sequences were as proposed by Origene (www.origene.com); ${ }^{2}$, primers were designed using Beacon Designer Probe/Primer Design Software (BioRad), validated in silico by Blast analysis, and their specificity tested by means of melting curve analysis and an electrophoresis in a high-resolution agarose. Forward and reverse primer sequences are denoted by " $F$ " and " $R$ ", respectively.

Prior analysis, technical replicates were averaged. The geometric mean of all $\mathrm{Cq}$ values in a given sample set was obtained and subtracted from the individual sample $\mathrm{Cq}(\triangle \mathrm{Cq})$ then linearized by $2^{\wedge} \Delta \mathrm{Cq}$ conversion and normalized to GAPDH. The obtained values were referred to as a normalized relative quantity (NRQ) [72] and subjected to statistical analysis.

\subsection{Statistical Analysis}

Normality of distribution was tested using a Kolmogorov-Smirnov test and homogeneity of variances using Levene's test. Data were analyzed using a $t$-test for independent samples, with Welch correction in case of unequal variances, or one-way ANOVA with a Tukey-Kramer posthoc test and presented as means with $95 \%$ confidence interval (CI). Transcriptional data were log-transformed and presented as geometric means with $95 \%$ CI. Paired data were analyzed using a $t$-test for paired samples. Logistic regression (stepwise model) with variables entered into the model if $p<0.05$ and removed if $p>0.1$ was used to select independent predictors of ESCC. The ROC curve analysis was applied to determine diagnostic power. The area under ROC curve (AUC), indicative of overall marker accuracy, as well as marker sensitivity and specificity, corresponding with optimal cut-off value, were calculated. The Fisher's exact test was applied for frequency analysis. Correlation analysis was conducted using Spearman rank correlation $(\rho)$ or Pearson correlation $(r)$, depending on the data character. The following rule of thumb was used to interpret the size of the correlation: 0.80 to 1.00 as very strong correlation, 0.60 to 0.80 as moderate correlation, 0.30 to 0.60 as fair correlation, $<0.30$ as poor correlation [73]. All calculated probabilities were two-tailed. The $p$-values $\leq 0.05$ were considered statistically significant. The entire analysis was conducted using MedCalc Statistical Software version 19.2 (MedCalc Software Ltd., Ostend, Belgium; https://www.medcalc.org; 2020).

Author Contributions: Conceptualization, I.B.-M. and M.K.-K.; data curation, D.D. and J.R.; formal analysis, I.B.-M., P.F., M.G.F. and M.K.-K.; investigation, I.B.-M., P.F., M.G.F., Ł.L. and M.K.-K.; methodology, P.F., M.G.F. and M.K.-K.; resources, D.D., J.R. and M.K.-K.; supervision, M.K.-K.; visualization, I.B.-M., P.F. and M.K.-K.; writing-original draft, I.B.-M. and M.K.-K.; writing—review and editing, I.B.-M., P.F., M.G.F., Ł.L., D.D., J.R. and M.K.-K. All authors have read and agreed to the published version of the manuscript.

Funding: This research received no external funding.

Acknowledgments: The authors would like to thank the Foundation of Wroclaw Medical University (FAM) and its Board Chairmen for financing a lease of BioRad Experion platform, CFX96 Real-Time PCR system, and Bioplex 200.

Conflicts of Interest: The authors declare no conflict of interest.

\section{Abbreviations}

ADMA Asymmetric dimethylarginine

Arg Arginine

ARG Arginase

ASS1 Argininosuccinate lyase

AUC Area under receiver operating characteristics (ROC) curve 


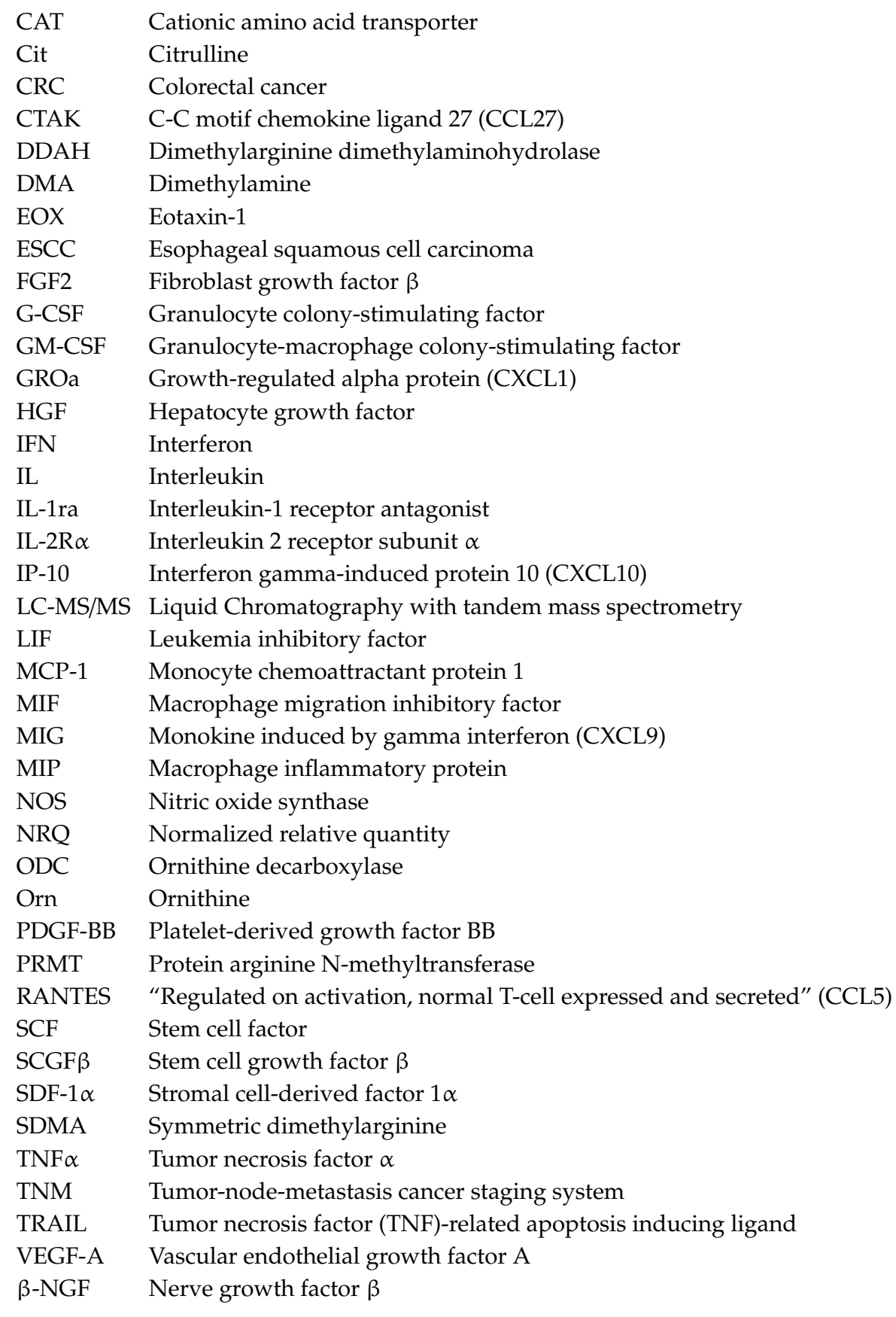

\section{References}

1. Abnet, C.C.; Arnold, M.; Wei, W. Epidemiology of Esophageal Squamous Cell Carcinoma. Gastroenterology 2018, 154, 360-373. [CrossRef] [PubMed]

2. Kumar, K.V.V.; Sagar, R.; Mathew, J. Squamous cell carcinoma: Esophagus. In Squamous Cell CarcinomaHallmark and Treatment Modalities; Daaboul, H.E., Ed.; IntechOpen Ltd.: London, UK, 2019. [CrossRef]

3. Yang, J.W.; Choi, Y.-L. Genomic profiling of esophageal squamous cell carcinoma (ESCC)—Basis for precision medicine. Pathol. Res. Pract. 2017, 213, 836-841. [CrossRef] [PubMed]

4. Hanahan, D.; Weinberg, R.A. Hallmarks of Cancer: The Next Generation. Cell 2011, 144, 646-674. [CrossRef] [PubMed]

5. Faubert, B.; Solmonson, A.; de Berardinis, R.J. Metabolic reprogramming and cancer progression. Science 2020, 368, e5473. [CrossRef] [PubMed] 
6. Bednarz-Misa, I.; Fortuna, P.; Diakowska, D.; Jamrozik, N.; Krzystek-Korpacka, M. Distinct Local and Systemic Molecular Signatures in the Esophageal and Gastric Cancers: Possible Therapy Targets and Biomarkers for Gastric Cancer. Int. J. Mol. Sci. 2020, 21, 4509. [CrossRef] [PubMed]

7. Bednarz-Misa, I.; Fleszar, M.G.; Zawadzki, M.; Kapturkiewicz, B.; Kubiak, A.; Neubauer, K.; Witkiewicz, W.; Krzystek-Korpacka, M. L-Arginine/NO Pathway Metabolites in Colorectal Cancer: Relevance as Disease Biomarkers and Predictors of Adverse Clinical Outcomes Following Surgery. J. Clin. Med. 2020, 9, 1782. [CrossRef]

8. Krzystek-Korpacka, M.; Fleszar, M.G.; Bednarz-Misa, I.; Lewandowski, Ł.; Szczuka, I.; Kempiński, R.; Neubauer, K. Transcriptional and Metabolomic Analysis of L-Arginine/Nitric Oxide Pathway in Inflammatory Bowel Disease and Its Association with Local Inflammatory and Angiogenic Response: Preliminary Findings. Int. J. Mol. Sci. 2020, 21, 1641. [CrossRef] [PubMed]

9. Keshet, R.; Erez, A. Arginine and the metabolic regulation of nitric oxide synthesis in cancer. Dis. Model. Mech. 2018, 11, dmm033332. [CrossRef]

10. Morris, S.M. Arginine Metabolism: Boundaries of Our Knowledge. J. Nutr. 2007, 137,S1602-S1609. [CrossRef]

11. Szefel, J.; Danielak, A.; Kruszewski, W.J. Metabolic pathways of L-arginine and therapeutic consequences in tumors. Adv. Med. Sci. 2019, 64, 104-110. [CrossRef]

12. Zou, S.; Wang, X.; Liu, P.; Ke, C.; Xu, S. Arginine metabolism and deprivation in cancer therapy. Biomed. Pharmacother. 2019, 118, 109210. [CrossRef] [PubMed]

13. Kus, K.; Kij, A.; Zakrzewska, A.; Jasztal, A.; Stojak, M.; Walczak, M.; Chlopicki, S. Alterations in arginine and energy metabolism, structural and signalling lipids in metastatic breast cancer in mice detected in plasma by targeted metabolomics and lipidomics. Breast Cancer Res. 2018, 20, 148. [CrossRef] [PubMed]

14. Fulton, M.D.; Brown, T.; Zheng, Y.G. The Biological Axis of Protein Arginine Methylation and Asymmetric Dimethylarginine. Int. J. Mol. Sci. 2019, 20, 3322. [CrossRef] [PubMed]

15. Torresano, L.; Nuevo-Tapioles, C.; Santacatterina, F.; Cuezva, J.M. Metabolic reprogramming and disease progression in cancer patients. Biochim. Biophys. Acta Mol. Basis Dis. 2020, 1866, 165721. [CrossRef] [PubMed]

16. Yoshida, M.; Hayashi, H.; Taira, M.; Isono, K. Elevated expression of the ornithine decarboxylase gene in human esophageal cancer. Cancer Res. 1992, 52, 6671-6675. [PubMed]

17. He, W.; Roh, E.; Yao, K.; Liu, K.; Meng, X.; Liu, F.; Wang, P.; Bode, A.M.; Surh, Y.-J. Targeting ornithine decarboxylase (ODC) inhibits esophageal squamous cell carcinoma progression. npj Precis. Oncol. 2017, 1, 13. [CrossRef]

18. Gerner, E.W.; Bruckheimer, E.; Cohen, A. Cancer pharmacoprevention: Targeting polyamine metabolism to manage risk factors for colon cancer. J. Boil. Chem. 2018, 293, 18770-18778. [CrossRef]

19. Auvinen, M.; Laine, A.; Paasinen-Sohns, A.; Kangas, A.; Kangas, L.; Saksela, O.; Andersson, L.C.; Hölttä, E. Human ornithine decarboxylase-overproducing NIH3T3 cells induce rapidly growing, highly vascularized tumors in nude mice. Cancer Res. 1997, 57, 3016-3025.

20. Gurpinar, E.; Grizzle, W.E.; Piazza, G. COX-Independent Mechanisms of Cancer Chemoprevention by Anti-Inflammatory Drugs. Front. Oncol. 2013, 3, 181. [CrossRef]

21. Meyskens, F.L.; McLaren, C.E.; Pelot, D.; Fujikawa-Brooks, S.; Carpenter, P.M.; Hawk, E.; Kelloff, G.; Lawson, M.J.; Kidao, J.; McCracken, J.; et al. Difluoromethylornithine Plus Sulindac for the Prevention of Sporadic Colorectal Adenomas: A Randomized Placebo-Controlled, Double-Blind Trial. Cancer Prev. Res. 2008, 1, 32-38. [CrossRef]

22. Bednarz-Misa, I.; Diakowska, D.; Krzystek-Korpacka, M.; Diakowska, R.; Misa, B.; Korpacka, K. Local and Systemic IL-7 Concentration in Gastrointestinal-Tract Cancers. Medicina 2019, 55, 262. [CrossRef] [PubMed]

23. Dakubo, G.D.; Jakupciak, J.P.; Birch-Machin, M.A.; Parr, R.L. Clinical implications and utility of field cancerization. Cancer Cell Int. 2007, 7, 2. [CrossRef] [PubMed]

24. Patel, A.; Tripathi, G.; Gopalakrishnan, K.; Williams, N.; Arasaradnam, R.P. Field cancerisation in colorectal cancer: A new frontier or pastures past? World J. Gastroenterol. 2015, 21, 3763-3772. [CrossRef] [PubMed]

25. Hulin, J.-A.; Gubareva, E.A.; Jarzebska, N.; Rodionov, R.N.; Mangoni, A.A.; Tommasi, S. Inhibition of Dimethylarginine Dimethylaminohydrolase (DDAH) Enzymes as an Emerging Therapeutic Strategy to Target Angiogenesis and Vasculogenic Mimicry in Cancer. Front. Oncol. 2020, 9, 1455. [CrossRef]

26. Buijs, N.; Oosterink, J.E.; Jessup, M.; Schierbeek, H.; Stolz, D.B.; Houdijk, A.P.; Geller, D.A.; van Leeuwen, P.A. A new key player in VEGF-dependent angiogenesis in human hepatocellular carcinoma: Dimethylarginine dimethylaminohydrolase 1. Angiogenesis 2017, 20, 557-565. [CrossRef] [PubMed] 
27. Sorrenti, V.; Vanella, L.; di Giacomo, C.; Acquaviva, R.; Santangelo, R.; Cardile, V.; Barbagallo, I.A.; Abraham, N.G. The DDAH/NOS pathway in human prostatic cancer cell lines: Antiangiogenic effect of L-NAME. Int. J. Oncol. 2011, 39, 1303-1310. [CrossRef] [PubMed]

28. Tain, Y.-L.; Hsu, C.-N. Toxic Dimethylarginines: Asymmetric Dimethylarginine (ADMA) and Symmetric Dimethylarginine (SDMA). Toxins 2017, 9, 92. [CrossRef]

29. Brankovic, B.; Stanojevic, G.; Stojanovic, I.; Veljkovic, A.; Kocic, G.; Janosevic, P.; Nestorovic, M.; Petrovic, D.; Djindjic, B.; Pavlovic, D.; et al. Nitric oxide synthesis modulation-A possible diagnostic and therapeutic target in colorectal cancer. J. BUON 2017, 22, 162-169.

30. Li, H.; Zhou, Y.; Zhao, A.; Qiu, Y.; Xie, G.; Jiang, Q.; Zheng, X.; Zhong, W.; Sun, X.; Zhou, Z.; et al. Asymmetric dimethylarginine attenuates serum starvation-induced apoptosis via suppression of the Fas (APO-1/CD95)/JNK (SAPK) pathway. Cell Death Dis. 2013, 4, e830. [CrossRef]

31. Yuan, M.; Zhu, H.; Xu, J.; Zheng, Y.; Cao, X.; Liu, Q. Tumor-Derived CXCL1 Promotes Lung Cancer Growth via Recruitment of Tumor-Associated Neutrophils. J. Immunol. Res. 2016, 2016, 1-11. [CrossRef]

32. Wang, N.; Liu, W.; Zheng, Y.-F.; Wang, S.; Yang, B.; Li, M.; Song, J.; Zhang, F.; Zhang, X.; Wang, Q.; et al. CXCL1 derived from tumor-associated macrophages promotes breast cancer metastasis via activating NF- $\mathrm{kB} / \mathrm{SOX} 4$ signaling. Cell Death Dis. 2018, 9, 880. [CrossRef] [PubMed]

33. Yu, S.; Yi, M.; Xu, L.; Qin, S.; Li, A.; Wu, K. CXCL1 as an Unfavorable Prognosis Factor Negatively Regulated by DACH1 in Non-small Cell Lung Cancer. Front. Oncol. 2020, 9, 9. [CrossRef] [PubMed]

34. Yang, Y.; Bedford, M.T. Protein arginine methyltransferases and cancer. Nat. Rev. Cancer 2012, 13, 37-50. [CrossRef]

35. Li, X.; Wang, C.; Jiang, H.; Luo, C. A patent review of arginine methyltransferase inhibitors (2010-2018). Expert Opin. Ther. Patents 2019, 29, 97-114. [CrossRef] [PubMed]

36. Musiani, D.; Giambruno, R.; Massignani, E.; Ippolito, M.R.; Maniaci, M.; Jammula, S.; Manganaro, D.; Cuomo, A.; Nicosia, L.; Pasini, D.; et al. PRMT1 Is Recruited via DNA-PK to Chromatin Where It Sustains the Senescence-Associated Secretory Phenotype in Response to Cisplatin. Cell Rep. 2020, 30, 1208-1222. [CrossRef]

37. Wei, H.-H.; Fan, X.-J.; Hu, Y.; Tian, X.-X.; Guo, M.; Fang, Z.-Y.; Wu, P.; Gao, S.-X.; Peng, C.; Yang, Y.; et al. A systematic survey of PRMT interactomes reveals key roles of arginine methylation in the global control of RNA splicing and translation. BioRxiv 2019. [CrossRef]

38. Zhou, W.; Yue, H.; Li, C.; Chen, H.; Yuan, Y. Protein arginine methyltransferase 1 promoted the growth and migration of cancer cells in esophageal squamous cell carcinoma. Tumor Boil. 2015, 37, 2613-2619. [CrossRef]

39. Zhao, Y.; Lu, Q.; Li, C.; Wang, X.; Jiang, L.; Huang, L.; Wang, C.; Chen, H. PRMT1 regulates the tumourinitiating properties of esophageal squamous cell carcinoma through histone $\mathrm{H} 4$ arginine methylation coupled with transcriptional activation. Cell Death Dis. 2019, 10, 359. [CrossRef]

40. Chuang, C.-Y.; Chang, C.-P.; Lee, Y.-J.; Lin, W.-L.; Wu, J.-S.; Cheng, Y.-W.; Li, C. PRMT1 expression is elevated in head and neck cancer and inhibition of protein arginine methylation by adenosine dialdehyde or PRMT1 knockdown downregulates proliferation and migration of oral cancer cells. Oncol. Rep. 2017, 38, 1115-1123. [CrossRef]

41. Xiao, W.; Chen, X.; Liu, L.; Shu, Y.; Zhang, M.; Zhong, Y. Role of protein arginine methyltransferase 5 in human cancers. Biomed. Pharmacother. 2019, 114, 108790. [CrossRef]

42. Ichikawa, T.; Shanab, O.; Nakahata, S.; Shimosaki, S.; Manachai, N.; Ono, M.; Iha, H.; Shimoda, K.; Morishita, K. Novel PRMT5-mediated arginine methylations of HSP90A are essential for maintenance of HSP90A function in NDRG2low ATL and various cancer cells. Biochim. Biophys. Acta Bioenerg. 2019, 1867, 118615. [CrossRef] [PubMed]

43. Kim, E.; Jang, J.; Park, J.G.; Kim, K.-H.; Yoon, K.; Yoo, B.C.; Cho, J.Y. Protein Arginine Methyltransferase 1 (PRMT1) Selective Inhibitor, TC-E 5003, Has Anti-Inflammatory Properties in TLR4 Signaling. Int. J. Mol. Sci. 2020, 21, 3058. [CrossRef] [PubMed]

44. Clemente, G.S.; van Waarde, A.; Antunes, I.F.; Dömling, A.; Elsinga, P.H. Arginase as a Potential Biomarker of Disease Progression: A Molecular Imaging Perspective. Int. J. Mol. Sci. 2020, 21, 5291. [CrossRef] [PubMed]

45. Wu, Y.; He, C.; Hu, S.; Hu, Z.; Li, Y.; Xing, X.; Du, X. Downregulation of ARG2 inhibits growth of colorectal cancer cells and increases expression of the $\mathrm{CD} 3 \zeta$ chain in co-cultured T-cells. Int. J. Clin. Exp. Med. 2019, $12,6946-6957$. 
46. Miret, J.J.; Kirschmeier, P.; Koyama, S.; Zhu, M.; Li, Y.Y.; Naito, Y.; Wu, M.; Malladi, V.S.; Huang, W.; Walker, W.; et al. Suppression of Myeloid Cell Arginase Activity leads to Therapeutic Response in a NSCLC Mouse Model by Activating Anti-Tumor Immunity. J. Immunother. Cancer 2019, 7, 32. [CrossRef]

47. Pedrosa, L.; Esposito, F.M.; Thomson, T.M.; Maurel, J. The Tumor Microenvironment in Colorectal Cancer Therapy. Cancers 2019, 11, 1172. [CrossRef]

48. Choi, W.; Lee, J.; Lee, J.; Lee, S.H.; Kim, S. Hepatocyte Growth Factor Regulates Macrophage Transition to the M2 Phenotype and Promotes Murine Skeletal Muscle Regeneration. Front. Physiol. 2019, 10, 914. [CrossRef]

49. Setty, B.A.; Smiley, N.P.; Pool, C.M.; Jin, Y.; Liu, Y.; Nelin, L.D. Hypoxia-induced proliferation of HeLa cells depends on epidermal growth factor receptor-mediated arginase II induction. Physiol. Rep. 2017, 5, e13175. [CrossRef]

50. Sormendi, S.; Wielockx, B. Hypoxia Pathway Proteins as Central Mediators of Metabolism in the Tumor Cells and Their Microenvironment. Front. Immunol. 2018, 9, 40. [CrossRef]

51. Kumar, V.; Gabrilovich, D.I. Hypoxia-inducible factors in regulation of immune responses in tumour microenvironment. Immunology 2014, 143, 512-519. [CrossRef]

52. Cheng, X.; Wang, H.; Zhang, X.; Zhao, S.; Zhou,Z.; Mu, X.; Zhao, C.; Teng, W. The Role of SDF-1/CXCR4/CXCR7 in Neuronal Regeneration after Cerebral Ischemia. Front. Mol. Neurosci. 2017, 11, 590. [CrossRef] [PubMed]

53. Delage, B.; Fennell, D.A.; Nicholson, L.; McNeish, I.; Lemoine, N.R.; Crook, T.; Szlosarek, P.W. Arginine deprivation and argininosuccinate synthetase expression in the treatment of cancer. Int. J. Cancer 2010, 126, 2762-2772. [CrossRef] [PubMed]

54. Miyamoto, T.; Lo, P.H.Y.; Saichi, N.; Ueda, K.; Hirata, M.; Tanikawa, C.; Matsuda, K. Argininosuccinate synthase 1 is an intrinsic Akt repressor transactivated by p53. Sci. Adv. 2017, 3, e1603204. [CrossRef]

55. Huang, H.-Y.; Wu, W.-R.; Wang, Y.-H.; Wang, J.-W.; Fang, F.-M.; Tsai, J.-W.; Li, S.-H.; Hung, H.-C.; Yu, S.-C.; Lan, J.; et al. ASS1 as a Novel Tumor Suppressor Gene in Myxofibrosarcomas: Aberrant Loss via Epigenetic DNA Methylation Confers Aggressive Phenotypes, Negative Prognostic Impact, and Therapeutic Relevance. Clin. Cancer Res. 2013, 19, 2861-2872. [CrossRef] [PubMed]

56. Moye, L.M.; Liu, Y.; Coarfa, C.; Putluri, N.; Rhoads, J.M. Plasma Urea Cycle Metabolites May Be Useful Biomarkers in Children With Eosinophilic Esophagitis. Front. Pediatr. 2019, 6, 423. [CrossRef] [PubMed]

57. Peñuelas, S.; Anido, J.; Prieto-Sánchez, R.M.; Folch, G.; Barba, I.; Cuartas, I.; García-Dorado, D.; Poca, M.-A.; Sahuquillo, J.; Baselga, J.; et al. TGF- $\beta$ Increases Glioma-Initiating Cell Self-Renewal through the Induction of LIF in Human Glioblastoma. Cancer Cell 2009, 15, 315-327. [CrossRef] [PubMed]

58. Albrengues, J.; Bourget, I.; Pons, C.; Butet, V.; Hofman, P.; Tartare-Deckert, S.; Féral, C.C.; Meneguzzi, G.; Gaggioli, C. LIF Mediates Proinvasive Activation of Stromal Fibroblasts in Cancer. Cell Rep. 2014, 7, 1664-1678. [CrossRef]

59. Nicola, N.A.; Babon, J.J. Leukemia inhibitory factor (LIF). Cytokine Growth Factor Rev. 2015, 26, 533-544. [CrossRef]

60. Pascual-García, M.; Bonfill-Teixidor, E.; Planas-Rigol, E.; Rubio-Perez, C.; Iurlaro, R.; Arias, A.; Cuartas, I.; Sala-Hojman, A.; Escudero, L.; Martínez-Ricarte, F.; et al. LIF regulates CXCL9 in tumor-associated macrophages and prevents CD8+ T cell tumor-infiltration impairing anti-PD1 therapy. Nat. Commun. 2019, 10, 2416. [CrossRef]

61. Mazzoldi, E.L.; Pavan, S.; Pilotto, G.; Leone, K.; Pagotto, A.; Frezzini, S.; Nicoletto, M.O.; Amadori, A.; Pastò, A. A juxtacrine/paracrine loop between C-Kit and stem cell factor promotes cancer stem cell survival in epithelial ovarian cancer. Cell Death Dis. 2019, 10, 412. [CrossRef]

62. Mego, M.; Cholujova, D.; Minárik, G.; Sedlackova, T.; Gronesova, P.; Karaba, M.; Benca, J.; Cingelova, S.; Cierna, Z.; Manasova, D.; et al. CXCR4-SDF-1 interaction potentially mediates trafficking of circulating tumor cells in primary breast cancer. BMC Cancer 2016, 16, 127. [CrossRef] [PubMed]

63. Levina, V.; Marrangoni, A.M.; Demarco, R.; Gorelik, E.; Lokshin, A.E. Drug-Selected Human Lung Cancer Stem Cells: Cytokine Network, Tumorigenic and Metastatic Properties. PLoS ONE 2008, 3, e3077. [CrossRef] [PubMed]

64. Yu, J.; Zhao, J.; Zhang, M.; Guo, J.; Liu, X.; Liu, L. Metabolomics studies in gastrointestinal cancer: A systematic review. Expert Rev. Gastroenterol. Hepatol. 2019, 14, 9-25. [CrossRef] [PubMed]

65. Konya, H.; Miuchi, M.; Satani, K.; Matsutani, S.; Yano, Y.; Tsunoda, T.; Ikawa, T.; Matsuo, T.; Ochi, F.; Kusunoki, Y.; et al. Asymmetric dimethylarginine, a biomarker of cardiovascular complications in diabetes mellitus. World J. Exp. Med. 2015, 5, 110-119. [CrossRef] [PubMed] 
66. Rysz, J.; Gluba-Brzozka, A.; Franczyk, B.; Jablonowski, Z.; Cialkowska-Rysz, A. Novel Biomarkers in the Diagnosis of Chronic Kidney Disease and the Prediction of Its Outcome. Int. J. Mol. Sci. 2017, 18, 1702. [CrossRef]

67. Di Franco, M.; Lucchino, B.; Conti, F.; Valesini, G.; Spinelli, F.R. Asymmetric Dimethyl Arginine as a Biomarker of Atherosclerosis in Rheumatoid Arthritis. Mediat. Inflamm. 2018, 2018, 1-13. [CrossRef]

68. Fleszar, M.G.; Wiśniewski, J.; Zboch, M.; Diakowska, R.; Gamian, A.; Krzystek-Korpacka, M. Targeted metabolomic analysis of nitric oxide/L-arginine pathway metabolites in dementia: Association with pathology, severity, and structural brain changes. Sci. Rep. 2019, 9, 13764. [CrossRef]

69. Fleszar, M.G.; Wisniewski, J.; Krzystek-Korpacka, M.; Misiak, B.; Frydecka, D.; Piechowicz, J.; Lorenc-Kukuła, K.; Gamian, A. Quantitative Analysis of 1-Arginine, Dimethylated Arginine Derivatives, 1-Citrulline, and Dimethylamine in Human Serum Using Liquid Chromatography-Mass Spectrometric Method. Chromatographia 2018, 81, 911-921. [CrossRef]

70. Krzystek-Korpacka, M.; Wiśniewski, J.; Fleszar, M.G.; Bednarz-Misa, I.; Bronowicka-Szydełko, A.; Gacka, M.; Masłowski, L.; Kędzior, K.; Witkiewicz, W.; Gamian, A. Metabolites of the Nitric Oxide (NO) Pathway Are Altered and Indicative of Reduced NO and Arginine Bioavailability in Patients with Cardiometabolic Diseases Complicated with Chronic Wounds of Lower Extremities: Targeted Metabolomics Approach (LC-MS/MS). Oxidative Med. Cell. Longev. 2019, 2019, 5965721. [CrossRef]

71. Chachaj, A.; Wisniewski, J.; Rybka, J.; Butrym, A.; Biedron, M.; Krzystek-Korpacka, M.; Fleszar, M.G.; Karczewski, M.; Wrobel, T.; Mazur, G.; et al. Asymmetric and symmetric dimethylarginines and mortality in patients with hematological malignancies-A prospective study. PLoS ONE 2018, 13, e0197148. [CrossRef]

72. Vandesompele, J.; de Preter, K.; Pattyn, F.; Poppe, B.; van Roy, N.; de Paepe, A.; Speleman, F. Accurate normalization of real-time quantitative RT-PCR data by geometric averaging of multiple internal control genes. Genome Boil. 2002, 3, 34. [CrossRef]

73. Akoğlu, H. User's guide to correlation coefficients. Turk. J. Emerg. Med. 2018, 18, 91-93. [CrossRef] [PubMed]

(C) 2020 by the authors. Licensee MDPI, Basel, Switzerland. This article is an open access article distributed under the terms and conditions of the Creative Commons Attribution (CC BY) license (http://creativecommons.org/licenses/by/4.0/). 